\title{
Universal Sex Differences in the Desire for Sexual Variety: Tests From 52 Nations, 6 Continents, and 13 Islands
}

\author{
David P. Schmitt \\ Bradley University
}

\author{
and 118 Members of the International Sexuality Description Project
}

\begin{abstract}
Evolutionary psychologists have hypothesized that men and women possess both long-term and shortterm mating strategies, with men's short-term strategy differentially rooted in the desire for sexual variety. In this article, findings from a cross-cultural survey of 16,288 people across 10 major world regions (including North America, South America, Western Europe, Eastern Europe, Southern Europe, Middle East, Africa, Oceania, South/Southeast Asia, and East Asia) demonstrate that sex differences in the desire for sexual variety are culturally universal throughout these world regions. Sex differences were evident regardless of whether mean, median, distributional, or categorical indexes of sexual differentiation were evaluated. Sex differences were evident regardless of the measures used to evaluate them. Among contemporary theories of human mating, pluralistic approaches that hypothesize sex differences in the evolved design of short-term mating provide the most compelling account of these robust empirical findings.
\end{abstract}

Among modern evolutionary theories of human mating, there is currently disagreement as to whether humans are solely designed for long-term monogamous mating (Hazan \& Zeifman, 1999; Miller \& Fishkin, 1997), are naturally inclined toward short-term promiscuous mating (Barash \& Lipton, 2001; Hrdy, 1981), or whether people possess a more "pluralistic" repertoire that includes both long-term and short-term mating strategies (e.g., Buss \& Schmitt, 1993; Chisholm, 1996; Kenrick, Sadalla, Groth, \& Trost, 1990). Pluralistic theorists often argue that a flexible mating design would provide important reproductive benefits to humans, allowing individuals to adaptively respond to a wide range of

David P. Schmitt, Department of Psychology, Bradley University; and 118 Members of the International Sexuality Description Project. A complete list of the 118 coauthors, listed alphabetically, can be found at the end of this article.

Except for the first author, all coauthors contributed equally to this article. The authors thank David M. Buss and Martie B. Haselton for their comments on an early version of this article. The authors thank those collaborators who were part of the International Sexuality Description Project but did not collect data relevant to the current study, including the following: Vijai N. Giri, Indian Institute of Technology, Kharagpur, India; Shamsul Haque, University of Dhaka, Dhaka, Bangladesh; Nhlanhla J. Mkhize, University of Natal, Scottsville, South Africa; Hmoud Olimat, University of Jordan, Amman, Jordan; Mithila B. Sharan, Indian Institute of Technology, Kharagpur, India; and R. Sookdew, University of Natal, Scottsville, South Africa. The authors also thank Susan Sprecher (USA), Del Paulhus (Canada), Glenn D. Wilson (England), Qazi Rahman (England), Alois Angleitner (Germany), Angelika Hofhansl (Austria), Mircea Miclea (Romania), Tamio Imagawa (Japan), Minoru Wada (Japan), Junichi Taniguchi (Japan), and Yuji Kanemasa (Japan) for their help with data collection and for contributing significantly to the samples used in this study.

Correspondence concerning this article should be addressed to David P. Schmitt, Department of Psychology, Bradley University, Peoria, Illinois 61625. E-mail: dps@bradley.edu familial, cultural, and ecological contexts (Belsky, 1999; Gangestad \& Simpson, 2000; Lancaster, 1989; F. A. Pedersen, 1991). Pluralistic theorists also suggest that humans can benefit from shifting their mating strategies during their life span, when in different stages of romantic relationships, and across the ovulatory cycle (Gangestad, 2001; Klusmann, 2002; Schmitt et al., 2002).

Most pluralistic approaches further postulate that men and women possess sex-specific design features of sexual desire that reliably generate more than one form of human mating (Bjorklund \& Shackelford, 1999; Hinde, 1984). For example, when men pursue short-term mates, they appear to do so motivated by adaptive desires for sexual variety-desires that lead short-term seeking men to functionally pursue numerous mating partners and to consent to sex relatively quickly (Buss \& Schmitt, 1993; Symons, 1979). In contrast, women's motivations for pursuing short-term mateships appear not to be rooted in the desire for numerous sexual partners and seem focused, instead, on selectively obtaining men of high status or genetic quality (Gangestad \& Thornhill, 1997; Smith, 1984). As a consequence of this sex difference in the specialized design of short-term mating psychology, pluralistic approaches usually predict that men-on the whole-will report greater desires for sexual variety than women will. On empirical examination, this sex difference has proven robust across numerous samples from the United States (Schmitt, Shackelford, Duntley, Tooke, \& Buss, 2001).

In this article, findings from a cross-cultural survey of 16,288 people across 10 major world regions (including North America, South America, Western Europe, Eastern Europe, Southern Europe, Middle East, Africa, Oceania, South/Southeast Asia, and East Asia) demonstrate that sex differences in the desire for sexual variety are cross-culturally universal. The results from this new survey, alongside additional research, support the view that when men pursue short-term mates they desire large numbers of sex partners and are generally quick to consent to sex, whereas when women pursue short-term mates they appear motivated more by 
partner quality than by partner quantity. This evidence also suggests that pluralistic theories of human mating are more likely to be correct than competing perspectives in which all humans are equipped with a singular (either long-term or short-term) mating strategy. Regardless of one's perspective, however, nearly all evolutionary theories of human mating are grounded in the seminal logic of parental investment theory (Trivers, 1972).

\section{Parental Investment Theory}

According to parental investment theory (Trivers, 1972), the relative proportion of parental investment-the time and energy devoted to the care of individual offspring-varies across the males and females of different species. In some species, males tend to provide more parental investment than females (e.g., the Mormon cricket; Gwynne, 1984). In other species, females possess the heavy-investing parental burdens (e.g., most mammals; Alcock, 1993; Clutton-Brock, 1991). One of Trivers's (1972) keen insights was to note that sex differences in parental investment burdens are systematically linked to processes of sexual selection in ways that potentially relate to mating strategies. Namely, within a given species, the sex that invests less in offspring is intrasexually more competitive, especially over gaining sexual access to members of the opposite sex. That is, the lesser investing sex (e.g., male elephant seals; Le Boeuf, 1974) is reliably more aggressive with their own sex, tends to die earlier, tends to mature later, and generally competes for mates with more vigor than the heavier investing sex (see also Alexander \& Noonan, 1979). Furthermore, the lesser investing sex of a species is intersexually more indiscriminate in mate choice than the heavier investing parent. The lesser investing sex is willing to mate more quickly, at low cost, and with more partners than is the heavier investing sex (Andersson, 1994; Bateson, 1983; Clutton-Brock \& Parker, 1992; Maynard Smith, 1977).

Much of the evidence in favor of parental investment theory (Trivers, 1972) has come from species where females happen to be the heavy-investing sex (e.g., Clutton-Brock, 1991). In these species, parental investment theory leads to the prediction that sexual selection has been more potent among males. On empirical examination, males of these species tend to display much more competitiveness with each other over sexual access to heavier investing females, and to exhibit more intrasexual competition through greater aggressiveness, riskier life history strategies, and earlier death than females (Archer \& Lloyd, 2002; Trivers, 1985). Lesser investing males are also less discriminate through intersexual mate choice, often seeking multiple partners and requiring less time before consenting to sex than females do (see Alcock, 1993; Geary, 1998).

Perhaps the most compelling support for parental investment theory (Trivers, 1972), however, has come from "sex-role reversed" species. In species where males are the heavy-investing parent (e.g., the red-necked phalarope; Reynolds, 1987), the processes of sexual selection are thought to have been more potent among females. Females of these species are expected to vie more ferociously for sexual access to heavy-investing males and to require little from males before consenting to sex. Evidence of this form of sexual differentiation has been documented among many "sex-role reversed" species including the red-necked phalarope, the Mormon cricket, katydids, dance flies, water bugs, seahorses, and a variety of fish species (Alcock, 1993; Alcock \& Gwynne,
1991). Parental investment theory, therefore, is not a theory about males always having more interest in low-cost, indiscriminate sex than females. Instead, it is a theory about differences in parental investment obligations systematically relating to sexual selection processes in ways that generate reliable sex differences in mating behavior across species (Buss \& Schmitt, 1993).

\section{How Does Parental Investment Theory Apply to Humans?}

Among humans, many males invest heavily as parents through the teaching of crucial social skills, by emotional nurturing children through difficult times, and by generally investing resources and prestige in their children (Hazan \& Diamond, 2000; Lovejoy, 1981; Zeifman \& Hazan, 1997). Nevertheless, human males typically invest considerably less in active parenting effort than females do across all known cultures (Low, 1989; Munroe \& Munroe, 1997; Quinn, 1977). In addition, men incur much lower levels of obligatory or "minimum" parental investment in offspring than women do. That is, men are not obligated to invest as much as women do to produce viable progeny (Symons, 1979).

Women are obligated, for example, to incur the costs of internal fertilization, placentation, and gestation in order to reproduce. The minimum physiological obligations of men are considerably lessrequiring only the contribution of sperm. Furthermore, all female mammals, including ancestral women, carried the obligatory investment burdens associated with lactation. Lactation can last several years in human foraging environments (Kelly, 1995), years during which it is harder for women to reproduce and invest in additional offspring than it is for men.

When looked at from the perspective of parental investment theory (Trivers, 1972), this human asymmetry in obligate parental investment burdens should result in the lesser investing sex (i.e., men) displaying greater intrasexual competitiveness and lower intersexual "choosiness" in mate preferences. In support of parental investment theory applying to humans, numerous studies have shown that men exhibit greater physical size and competitive aggression (Archer \& Lloyd, 2002; Harvey \& Reynolds, 1994; Hyde, 1986), riskier life history strategies (Daly \& Wilson, 1988), relatively delayed maturation (Geary, 1998), and earlier death than women do across all known cultures (Alexander \& Noonan, 1979). In addition, men's mate preferences are, as predicted, almost always less "choosy" or discriminating than women's, especially in the context of short-term mating (Buss \& Schmitt, 1993; Kenrick et al., 1990; Regan, 1998a, 1998b; Regan \& Berscheid, 1997; Simpson \& Gangestad, 1992). On the basis of parental investment theory, therefore, men are the lesser investing sex of our species and should be more inclined toward low-cost, less discriminate mating than women.

\section{Sexual Strategies Theory}

A decade ago, Buss and Schmitt (1993) extended Trivers's (1972) theory by proposing sexual strategies theory (SST). According to SST, men and women have evolved a complex repertoire of mating strategies. One strategy within this repertoire is long-term committed mating. Long-term mating is typically marked by extended courtship, heavy investment, the emotion of love, and the dedication of resources over a long temporal span to the mating relationship and any offspring that ensue. Another strategy within this repertoire is short-term mating, defined as a 
fleeting sexual encounter such as a one-night stand. Between the ends of this temporal continuum are brief affairs, prolonged romances, and other intermediate-term relationships. Which sexual strategy or mix of strategies an individual pursues is predicted to be contingent on factors such as opportunity, personal mate value, sex ratio in the relevant mating pool, parental influences, regnant cultural norms, and other features of social and personal context (see also Buss, 1994; Gangestad \& Simpson, 2000; Schmitt, 2003a).

Although SST views both sexes as having long-term and shortterm strategies within their repertoire, men and women are predicted to differ fundamentally in certain respects. In long-term mating, for example, the sexes are predicted to differ in their mate preferences. Men are hypothesized to place a greater premium on signals of fertility and reproductive value, such as a woman's youth and physical appearance. Women, in contrast, are hypothesized to place a greater premium on a man's status, maturity, and resources-cues relevant to his potential long-term provisioning (Buss \& Schmitt, 1993; Ellis, 1992). In each case, the differing qualities that men and women preferentially desire are thought to help solve the adaptive problems that men and women have faced over human evolutionary history.

According to SST, both sexes are also hypothesized to pursue short-term mating in delimited contexts, but for different reproductive reasons that reflect sex-specific adaptive problems. For women, the asymmetry in obligatory parental investment leaves them little to gain in reproductive output by engaging in indiscriminate, short-term sex with numerous partners (see also Bjorklund \& Shackelford, 1999; Hinde, 1984). However, for men the potential reproductive benefits from less discriminate mating can be profound. Consider that one man can produce as many as 100 offspring by indiscriminately mating with 100 women in a given year, whereas a man who is monogamous will tend to have only one child with his partner during that same time period. In evolutionary currencies, this represents a strong selective pressure-and a potent adaptive problem-for men's mating strategies to favor at least some desire for sexual variety (Barash \& Lipton, 2001; Buss \& Schmitt, 1993).

In contrast, whether a woman mates with 100 men or is monogamously bonded with only one man, she will still tend to produce only one child in a given year. The potential reproductive benefits from multiple mating with numerous partners, therefore, are much higher for men than for women (Bateman, 1948; Symons, 1979). It is important to note that women can reap evolutionary benefits from short-term mating as well (Greiling \& Buss, 2000). A key caveat to this, however, is that women's short-term strategy appears to center more on obtaining men of high status or genetic quality rather than numerous men in high-volume quantity (Banfield \& McCabe, 2001; Carroll, Volk, \& Hyde, 1985; Townsend, 1995; Wilson, 1987).

A key premise of SST, therefore, is that both sexes can reap reproductive rewards from engaging in short-term mating under certain circumstances. Even though both sexes may adaptively pursue short-term mateships, however, men and women are hypothesized by SST to differ in the evolved psychological design of their short-term strategies. According to SST, three of the more distinctive features of men's short-term mating psychology are as follows: (a) men possess a greater desire than women do for a variety of sexual partners, (b) men require less time to elapse than women do before consenting to sexual intercourse, and (c) men tend to more actively seek short-term mateships than women do (Buss \& Schmitt, 1993, p. 210). In each case, these hypothesized desires function to help solve men's adaptive problem of obtaining large numbers of short-term partners.

This suite of hypothesized sex differences has been well supported among studies of college student and community samples from the United States (for a review, see Schmitt, Shackelford, \& Buss, 2001). However, sex differences in the desire for sexual variety have never been directly tested across large numbers of cultures. Indeed, no studies have been conducted where these three hypotheses were tested in non-Western cultures. The primary objective of the present study was to evaluate whether sex differences in the desire for sexual variety are robust across a broad range of human cultures. Finding universal sex differences in the desire for sexual variety would support parental investment theory (Trivers, 1972), SST (Buss \& Schmitt, 1993) as well as other pluralistic theories of human mating (Gangestad \& Simpson, 2000). Logically, any theory that posits all humans share a singular strategy (whether long-term or short-term) would find it more difficult to account for universal sex differences in the desire for sexual variety.

\section{Method}

\section{Samples}

The research reported in this article is a result of the International Sexuality Description Project (ISDP), a collaborative effort of over 100 social, behavioral, and biological scientists from 10 world regions. As seen in Table 1, three nations were sampled from the world region of North America. The Canadian national sample included three independent, English-speaking subsamples from the Canadian provinces of Ontario, Alberta, and British Columbia, and one French-speaking subsample from Quebec. The French-speaking participants were administered the ISDP survey as translated/back-translated into French. The translation/backtranslation procedures are addressed later. Thirteen subsamples were obtained from the United States of America (USA). This included at least one subsample from the states of New York, Illinois, Kentucky, South Carolina, Florida, Alabama, Texas, New Mexico, Idaho, California, and Hawaii. In the subsample from Hawaii, $75 \%$ of individuals described themselves as "Asian American" or "Native Hawaiian." The subsamples from mainland USA consisted of 66\% European American (non-Hispanic), 10\% African American, 8\% Hispanic American, 5\% Asian American, 2\% Native American, and $9 \%$ other or nondescriptive. The North American world region also included a sample from the nation of Mexico. The Mexican sample was comprised of general community members who volunteered for the study (see Table 1). Community samples in the ISDP tended to be related to colleges and universities (e.g., many were employed by the local educational institutions), and so should not be considered as completely independent of the college-related limitations of most ISDP national samples.

Five nations were sampled from the world region of South America. Eight nations from Western Europe, 11 nations from Eastern Europe, and six samples from Southern Europe were sampled as part of the ISDP. It is important to acknowledge that the placement of cultures into these three European "regions" may be viewed by some as problematic, and certainly that more than three basic regions exist in Europe, including Northern, Central, and other divisions. However, given the number and geography of nations included in the ISDP, these three divisions were chosen to economize the presentation of findings while maintaining genuine regional variation across the European continent.

Four national samples from the Middle East world region were included in the ISDP, as were seven nations from Africa. However, the samples from Jordan and South Africa were not administered the sex-related 
Table 1

Sample Sizes, Sampling Type, and Language of Survey Across the 52 Nations and 10 World Regions of the International Sexuality Description Project (ISDP)

\begin{tabular}{|c|c|c|c|c|}
\hline \multirow[b]{2}{*}{ World regions } & \multicolumn{2}{|c|}{ Sample size } & \multirow[b]{2}{*}{ Sample type } & \multirow[b]{2}{*}{ Language } \\
\hline & Men & Women & & \\
\hline North America & 1,385 & 2,384 & & \\
\hline Canada & 368 & 656 & College students & English/French \\
\hline Mexico & 106 & 109 & Community-based & Spanish \\
\hline United States of America & 911 & 1,619 & College students & English \\
\hline South America & 364 & 433 & & \\
\hline Argentina & 110 & 136 & College students & Spanish \\
\hline Bolivia & 87 & 83 & College students & Spanish \\
\hline Brazil $^{\mathrm{a}}$ & 41 & 54 & College students & Portuguese \\
\hline Chile $^{\mathrm{a}}$ & 25 & 60 & College students & Spanish \\
\hline Peru & 101 & 100 & College students & Spanish \\
\hline Western Europe & 1,083 & 1,850 & & \\
\hline Austria & 207 & 259 & College/community & German \\
\hline Belgium (Flanders) & 163 & 354 & College students & Dutch (Flemish) \\
\hline Finland $^{\mathrm{a}}$ & 32 & 86 & Community-based & Finnish \\
\hline France & 58 & 71 & College students & French \\
\hline Germany & 289 & 490 & College/community & German \\
\hline Netherlands & 115 & 126 & College students & Dutch \\
\hline Switzerland & 84 & 127 & College students & German \\
\hline United Kingdom & 135 & 337 & College/community & English \\
\hline Eastern Europe & 1,209 & 1,542 & & \\
\hline Croatia & 113 & 109 & College students & Croatian \\
\hline Czech Republic & 103 & 123 & College students & Czech \\
\hline Estonia & 78 & 109 & College students & Estonian \\
\hline Latvia & 90 & 102 & College students & Latvian \\
\hline Lithuania $^{\mathrm{a}}$ & 46 & 47 & College students & Lithuanian \\
\hline Poland & 305 & 527 & College students & Polish \\
\hline Romania & 120 & 125 & College students & Romanian \\
\hline Serbia & 100 & 100 & College students & Serbian \\
\hline Slovakia & 81 & 94 & College students & Slovak \\
\hline Slovenia & 73 & 106 & College students & Slovenian \\
\hline Ukraine & 100 & 100 & College/community & Ukrainian \\
\hline Southern Europe & 495 & 836 & & \\
\hline Cyprus $^{\mathrm{a}}$ & 24 & 35 & College students & Greek \\
\hline Greece $^{a}$ & 47 & 180 & College students & Greek \\
\hline Italy & 92 & 108 & College/community & Italian \\
\hline Malta & 128 & 194 & College students & English \\
\hline Portugal & 110 & 142 & College students & Portuguese \\
\hline Spain & 94 & 177 & College students & Spanish \\
\hline Middle East & 503 & 548 & & \\
\hline Israel & 179 & 211 & College students & Hebrew \\
\hline Lebanon & 120 & 134 & College students & English \\
\hline Turkey & 204 & 203 & College/community & Turkish \\
\hline Africa & 611 & 472 & & \\
\hline Botswana & 97 & 116 & College students & English \\
\hline Congo, Dem. Rep. of & 122 & 64 & College/community & French \\
\hline Ethiopia & 124 & 84 & College/community & English \\
\hline Morocco & 88 & 78 & College students & English \\
\hline Tanzania, ${ }^{a}$ United Rep. of & 80 & 30 & College students & English \\
\hline Zimbabwe & 100 & 100 & College students & English \\
\hline Oceania & 392 & 522 & & \\
\hline Australia & 200 & 286 & College students & English \\
\hline Fiji \& Pacific Islands & 79 & 78 & College/community & English \\
\hline New Zealand & 113 & 158 & College students & English \\
\hline South/Southeast Asia & 213 & 289 & & \\
\hline Indonesia $^{\mathrm{a}}$ & 48 & 43 & College students & Indonesian \\
\hline Malaysia $^{\mathrm{a}}$ & 46 & 85 & College students & Malay \\
\hline Philippines & 119 & 161 & College students & English \\
\hline East Asia & 567 & 590 & & \\
\hline Hong Kong (China) & 100 & 101 & College students & English \\
\hline Japan & 156 & 101 & College students & Japanese \\
\hline Korea, Rep. of & 195 & 295 & College students & Korean \\
\hline Taiwan & 116 & 93 & College students & Mandarin \\
\hline Worldwide ISDP sample: & 6,822 & 9,466 & College/community & 27 languages \\
\hline
\end{tabular}

Note. Most samples primarily comprised college students; some included general members of the community. All samples were convenience samples. Further details on sampling methods within each nation are available from the authors. Dem. = Democratic; Rep. $=$ Republic.

${ }^{a}$ Only a subset of participants from larger national samples were administered and/or fully completed all sex-related measures. Samples from Jordan, South Africa, India, and Bangladesh were also included in the ISDP, but participants in those samples were not administered the measures used in this study. 
measures analyzed in this study. Three nations from Oceania were included in the ISDP. The Oceanic sample from Fiji was collected at the University of the South Pacific, a true regional university. Although a large number of participants were from Fiji, a significant number came from surrounding nations within the Pacific Island region. Consequently, this national sample was referred to as "Fiji and Pacific Islands." Five nations from South or Southeast Asia were included in the ISDP, including national samples from India, Bangladesh, Malaysia, Indonesia, and the Philippines. However, the samples from India and Bangladesh were not administered the sex-related measures analyzed in this study. Finally, four national samples from East Asia were included, one sample each from Hong Kong (now a part of the People's Republic of China), Taiwan (Republic of China), and Japan, and two subsamples were accumulated from the Republic of (South) Korea.

Overall, this collection of national samples represented a diverse array of ethnic, geographic, and linguistic categories. In total, the many samples of the ISDP represent 6 continents, 13 islands (including Cyprus, Malta, Fiji, New Zealand, Indonesia, Malaysia, the Philippines, Hong Kong, Japan, Taiwan, Hawaii, Ireland, and Britain), 27 languages, and 52 nations (see Table 1). Most samples were comprised of college students (indicated in Table 1 under the Sample type column by "College students" or "college"); some included general members of the community (indicated by "Community-based" or "Community"), though these samples were usually somewhat related to the local college or university. All samples were convenience samples. Most samples were recruited as volunteers, some received course credit for participation, and others received a small monetary reward for their participation. All samples were administered an anonymous self-report survey, and most surveys were returned through sealed envelope and/or the usage of a drop box. Return rates for college student samples tended to be relatively high (around 95\%), though this number was lower in some cultures. Return rates for community samples were around $50 \%$.

Not all participants received the full ISDP survey-the national samples from Jordan, South Africa, India, and Bangladesh were part of the ISDP but were eliminated from the present analyses because none were administered the sex-related measures that are the focus of the current investigation. Further details on the sampling and assessment procedures within each of the world regions and national samples are provided elsewhere (Schmitt et al., in press) and are available from the authors.

\section{Procedure}

All collaborators were asked to administer an anonymous nine-page survey to at least 100 men and 100 women. Some nations, such as the United States and Canada, contained numerous convenience samples and so the national sample size was much larger than 200. As seen in Table 1, several national samples failed to reach the designated sample size of 100 men and 100 women. Because of the small sample sizes for individual nations, the 52 nations were collapsed into 10 basic world regions when conducting key statistical analyses. The 10 world regions included North America $(N=1,385$ men, 2,384 women), South America $(N=364$ men, 433 women), Western Europe ( $N=1,083$ men, 1,850 women), Eastern Europe ( $N=1,209$ men, 1,542 women), Southern Europe $(N=495$ men, 836 women), the Middle East ( $N=503$ men, 548 women), Africa $(N=$ 611 men, 472 women), Oceania $(N=392$ men, 522 women $)$, South/ Southeast Asia $(N=213$ men, 289 women), and East Asia $(N=567$ men, 590 women). For each world region, at least 200 participants (including the key level of at least 100 men and 100 women) were included, providing the necessary statistical power (when setting $\beta=.90, \alpha=.05$, and when looking for an effect moderate in size; Cohen, 1988) to make within-region sex-difference analyses substantive and meaningful.

All participants were provided with a brief description of the study, including the following written instructions:

This questionnaire is entirely voluntary. All your responses will be kept confidential and your personal identity will remain anonymous. No identifying information is requested on this survey, nor will any such information be added later to this survey. If any of the questions make you uncomfortable, feel free not to answer them. You are free to withdraw from this study at any time for any reason. This series of questionnaires should take about 20 min to complete. Thank you for your participation.

The full instructional set provided by each collaborator varied, however, and was adapted to fit the specific culture and type of sample. Details on incentives and cover stories used across samples are available from the authors.

\section{Measures}

Translation procedures. Researchers from nations where English was not the primary language were asked to conduct a translation/backtranslation procedure and administer the ISDP in their native language. This process typically involved the primary collaborator translating the measures into the native language of the participants, and then having a second person back-translate the measures into English. Differences between the original English and the back-translation were discussed, and mutual agreements were made as to the most appropriate translation. This "etic" procedure tries to balance the competing needs of making the translation meaningful and naturally readable to the native participants, while preserving the integrity of the original measure and its constructs (Brislin, 1980; Church, 2001). As seen in Table 1, this process resulted in the survey being translated into 27 different languages. Samples from Morocco, Ethiopia, Fiji, the Philippines, and Hong Kong were administered the survey in English, but certain terms and phrases were annotated to clarify what were thought to be confusing words for the participants. The translation of the ISDP survey into the Flemish dialect of Dutch used only a translation procedure, as this involved mainly word variant changes from the original Dutch. Finally, pilot studies were conducted in several testing sites, in part to clarify translation and comprehension concerns.

Demographic measure. Each sample was first presented with a demographic measure entitled "Confidential Personal Information." This measure included questions about sex (male, female), age, sexual orientation (heterosexual, homosexual, bisexual), and current relationship status (married, cohabiting, dating one person exclusively, not currently involved with anyone).

Number of partners measure. The "Number of Partners" measure originally used by Buss and Schmitt (1993) was adapted for use in the ISDP. The Number of Partners measure contains 11 open-ended scales for evaluating the number of sexual partners desired at differing time intervals The Number of Partners measure instructed participants to fill in openended blanks with their responses concerning the following: "Ideally, how many different sex partners would you like to have..." over different periods of time ranging from " 1 month" to "your remaining lifetime."

Time known measure. The "Time Known" measure originally used by Buss and Schmitt (1993) was adapted for use in the ISDP. The Time Known measure asked participants to rate on a 6-point scale ranging from +3 (definitely yes) to -3 (definitely not) the degree to which, "If the conditions were right, would you consider having sexual intercourse with someone you viewed as desirable if ..." they had known that person for varying amounts of time ranging from 5 years to $1 \mathrm{hr}$.

Short-term seeking measure. Included in the ISDP was a measure of "Short-Term Seeking" developed by Buss and Schmitt (1993). This oneitem scale asked the extent to which participants were actively seeking short-term mating partners and ranged from 1 (not at all currently seeking) to 7 (strongly currently seeking).

\section{Results}

The primary objective of this research was to evaluate whether men and women across a variety of cultures differ in their desires for sexual variety. According to SST, men's short-term mating 
psychology is adaptively rooted in a desire for sexual variety such that men should show evidence of preferring "larger numbers of sexual partners over time than women" (see Prediction 2 of Hypothesis 1 of SST; Buss \& Schmitt, 1993, p. 210). Buss and Schmitt (1993) developed their Number of Partners measure to address this prediction. It should be noted that this prediction does not expect all men to engage in short-term mating, nor that all women should pursue only long-term relationships. Instead, SST predicts that those men who pursue short-term mates are motivated by a desire for sexual variety, whereas others (long-term seeking men, and women seeking long-term or short-term mates) are not. Thus, SST expects that the overall distribution of men's and women's desires for large numbers of partners will significantly differ, with more men than women (especially short-term seeking men) expressing desires for large numbers of partners. This sex difference can be evaluated using several statistical tools. Because mean-level sex differences using the Number of Partners measure have been a point of some controversy (Miller \& Fishkin, 1997; W. C. Pedersen, Miller, Putcha-Bhagavatula, \& Yang, 2002), a basic replication of these mean-level sex differences across various regions of the world was addressed first.

\section{Sex Differences in the Desire for Sexual Variety: Mean- Level Analyses}

A winsorization or trimming process similar to the techniques used by Buss and Schmitt (1993), and replicated by W. C. Pedersen et al. (2002), was used to eliminate a few inordinately high scores on the Number of Partners measure. Buss and Schmitt had originally truncated to 99 all scores of 100 and above in their original research. In the present analysis, all those who reported a desire for 100 or more sexual partners in a given time interval were simply eliminated from consideration in mean-level analyses (e.g., across all world regions, a total of 6 men and no women were eliminated for the "1-month" time interval). Although such extreme desires may be informative about a few people's sexual psychology and could have real-life implications for members of the opposite sex, these outliers were excluded so as not to affect men's and women's mean levels of sexual desire.

Across all samples combined, men desired significantly larger numbers of sexual partners than women. As seen in
Table 2, this was true across every time interval, ranging from "in the next month" to "in the next 30 years." Buss and Schmitt's (1993) finding of smaller mean-level sex differences at the earliest time interval, in the next month $(d=0.40)$, was also replicated.

The remainder of the current set of analyses conservatively focused on sex differences in the number of different sexual partners desired "in the next month" and "in the next 30 years" across each of the 10 world regions. The 1-month time interval was chosen because it economized data presentation and focused on relatively short-term sexual desires. In addition, previous research has shown the smallest sex differences tend to be found at the 1-month time interval (Buss \& Schmitt, 1993), making it likely that if sex differences in the number of partners desired are significant at the 1-month time interval, they also will significantly differ at later time intervals. The "next 30 years" time interval was chosen for presentation economy and because it has been the special focus of previous criticism (W. C. Pedersen et al., 2002). Full statistical analyses based on other time intervals, on scalar combinations of time intervals, on weighted analyses across regions, and using meta-analytic techniques across regions (see Schmitt, 2003a) demonstrated similar results and are available from the authors.

The winsorization technique for "in the next month" involved eliminating only 1 man from North America, 2 men from Western Europe, and 3 men from Eastern Europe-one of whom reported desires for 1,000 sexual partners in the next month. No woman from any region of the world reported a desire for 100 or more sexual partners in the next month. As listed in Table 3, men's mean levels of partners desired were significantly higher than women's mean levels within every world region. For example, in North America the mean level for men was 1.66 for partners desired in the next month. The mean level of desire for women was for 0.63 partners, $t(3582)=12.53, p<.001$. According to Cohen's $d$ statistic, the magnitude of the difference between North American men and women $(d=0.43)$ was close to moderate in size. Generally, differences of 0.20 are considered small, 0.50 are considered moderate, and 0.80 are considered large (Cohen, 1988). The effect of world region was also significant, $F(9$, $13552)=15.87, p<.001$, as was the interaction of sex and world region, $F(9,13552)=3.36, p<.001$. However, these significant

Table 2

Mean-Level Sex Differences in the Number of Sexual Partners Desired Over Time

\begin{tabular}{|c|c|c|c|c|c|c|}
\hline \multirow[b]{2}{*}{ Time intervals } & \multicolumn{2}{|c|}{ Men } & \multicolumn{2}{|c|}{ Women } & \multirow[b]{2}{*}{$t$} & \multirow[b]{2}{*}{$d$} \\
\hline & $M$ & $S D$ & $M$ & $S D$ & & \\
\hline Next month & 1.87 & 3.99 & 0.78 & 0.79 & $23.56^{* * *}$ & 0.40 \\
\hline 6 months & 2.63 & 5.40 & 0.99 & 1.38 & $25.73 * *$ & 0.44 \\
\hline 1 year & 3.36 & 6.65 & 1.18 & 1.68 & 27.80 ** & 0.47 \\
\hline 2 years & 4.24 & 8.43 & 1.42 & 2.21 & $28.03^{* *}$ & 0.48 \\
\hline 3 years & 4.93 & 9.82 & 1.61 & 2.64 & $28.03 * *$ & 0.49 \\
\hline 4 years & 5.32 & 10.57 & 1.77 & 2.92 & $27.68 * *$ & 0.48 \\
\hline 5 years & 5.64 & 10.88 & 1.95 & 3.38 & $27.63 * *$ & 0.48 \\
\hline 10 years & 5.95 & 11.35 & 2.17 & 3.78 & $26.79 * *$ & 0.47 \\
\hline 20 years & 6.40 & 12.34 & 2.34 & 4.27 & $26.28 * *$ & 0.46 \\
\hline 30 years & 6.62 & 12.71 & 2.47 & 4.62 & $25.78^{* *}$ & 0.46 \\
\hline
\end{tabular}


Table 3

Mean-Level Sex Differences in the Number of Sexual Partners Desired "in the Next Month" Across 10 World Regions

\begin{tabular}{|c|c|c|c|c|c|c|}
\hline \multirow[b]{2}{*}{ World region } & \multicolumn{2}{|c|}{ Men } & \multicolumn{2}{|c|}{ Women } & \multirow[b]{2}{*}{$t$} & \multirow[b]{2}{*}{$d$} \\
\hline & $M$ & $S D$ & $M$ & $S D$ & & \\
\hline North America & 1.66 & 3.77 & 0.63 & 0.76 & $12.53 * *$ & 0.43 \\
\hline South America & 2.11 & 3.82 & 0.78 & 0.69 & $6.16^{* *}$ & 0.49 \\
\hline Western Europe & 1.82 & 3.68 & 0.93 & 0.84 & $8.85 * *$ & 0.37 \\
\hline Eastern Europe & 2.43 & 5.49 & 1.01 & 0.88 & $8.82 * *$ & 0.38 \\
\hline Southern Europe & 2.01 & 3.08 & 0.90 & 0.90 & $8.94 * *$ & 0.53 \\
\hline Middle East & 2.54 & 5.40 & 0.88 & 0.55 & $6.29 * *$ & 0.42 \\
\hline Africa & 1.33 & 1.99 & 0.64 & 0.70 & $6.48 * *$ & 0.44 \\
\hline Oceania & 1.77 & 3.69 & 0.82 & 0.70 & $5.37 * *$ & 0.38 \\
\hline South/Southeast Asia & 1.98 & 4.05 & 0.88 & 0.55 & $3.00 * *$ & 0.39 \\
\hline East Asia & 1.25 & 2.21 & 0.35 & 0.70 & $9.09 * *$ & 0.53 \\
\hline
\end{tabular}

** $p<.001$.

findings may be a consequence of very large sample sizes because the pattern of sexual differentiation was generally very similar across world regions, with $d$ s concentrating around a moderate sex difference, ranging from 0.37 in Western Europe to 0.53 in Southern Europe and East Asia. ${ }^{1}$

On the basis of these cross-cultural ISDP findings, it seems reasonable to conclude that sex differences in the mean number of partners desired "in the next month" are culturally universal, at least across the 10 major world regions investigated by the ISDP. The same conclusion was reached when looking at meanlevel sex differences in the number of partners desired "in the next 30 years." As seen in Figure 1, men desired larger numbers of sex partners in the next 30 years in every major region of the world. All of the sex differences displayed in Figure 1 were statistically significant, including the results from Africa. In Africa, the mean level for men was to ideally want 2.00 sexual partners in the next 30 years $(S D=5.59)$, whereas for women the mean level was to desire 1.15 sexual partners $(S D=2.53)$, $t(853)=2.76, p<.01, d=0.19$. One reason for the relatively low-level reporting of desires for sexual variety in this world region may involve the high rates of HIV/AIDS in some ISDP African nations (e.g., Botswana). In any case, sex differences in the mean number of partners desired "in the next month" and "in the next 30 years" were cultural universals as explored by the ISDP, and these cross-cultural findings support the view that men desire more sexual partners than women, perhaps because of the adaptive nature of men's fundamental mating psychology.

\section{Sex Differences in the Desire for Sexual Variety: Nonparametric Analyses}

One of the primary criticisms levied against Prediction 2 from Hypothesis 1 of SST (see Miller \& Fishkin, 1997; W. C. Pedersen et al., 2002) concerns the use of mean-level statistics to evaluate data from the Number of Partners measure (Buss \& Schmitt, 1993). In response to this concern, Schmitt and his colleagues (Schmitt, Shackelford, \& Buss, 2001; Schmitt, Shackelford, Duntley et al., 2001) performed median tests on responses to the
Number of Partners measure across replication samples from four states within the United States (i.e., New York, Florida, Illinois, and Texas). In every case, the median male wanted more sexual partners than the median female. However, to more fully evaluate Prediction 2 from Hypothesis 1 of SST, median tests were performed on the responses of 16,288 people from the 10 world regions of the ISDP.

Listed along the left side of Table 4 are median tests for the number of sexual partners desired by men and women "in the next month" across 10 world regions. In all world regions, median tests indicated that the distributions of men and women were significantly different. This cultural universal was found across both "in the next month" and "in the next 30 years" time intervals. Full analyses from all time intervals are available from the authors. The present median-based results confirm that sex differences in the desire for sexual variety are not limited to comparisons of mean-level desires. The median man clearly seeks larger numbers of partners than the median woman across all world regions of the ISDP, providing additional support for the SST view that men who pursue short-term sexual strategies do so on the basis of a desire for sexual variety and multiple mating partners.

Also listed in Table 4 are rankings and Mann-Whitney $U$ tests for differences between men's and women's distributions. These key distributional tests document that the distributions of men's and women's desires for sexual variety were significantly different across all cultures. Of importance, these tests are unaffected by extreme scores and evaluate only whether, as predicted by SST, men and women show fundamental differences in their distributions of desires for sexual variety. Similar to mean and median

\footnotetext{
${ }^{1}$ On the basis of post hoc analyses (e.g., Tukey's honestly significant difference [HSD] test), the main effect of world region appeared driven by higher desires for sexual variety in Eastern Europe and the Middle East, and lower levels in Africa and East Asia. The interaction effect appeared driven primarily by larger sex differences in South America, Southern Europe, and East Asia.
} 


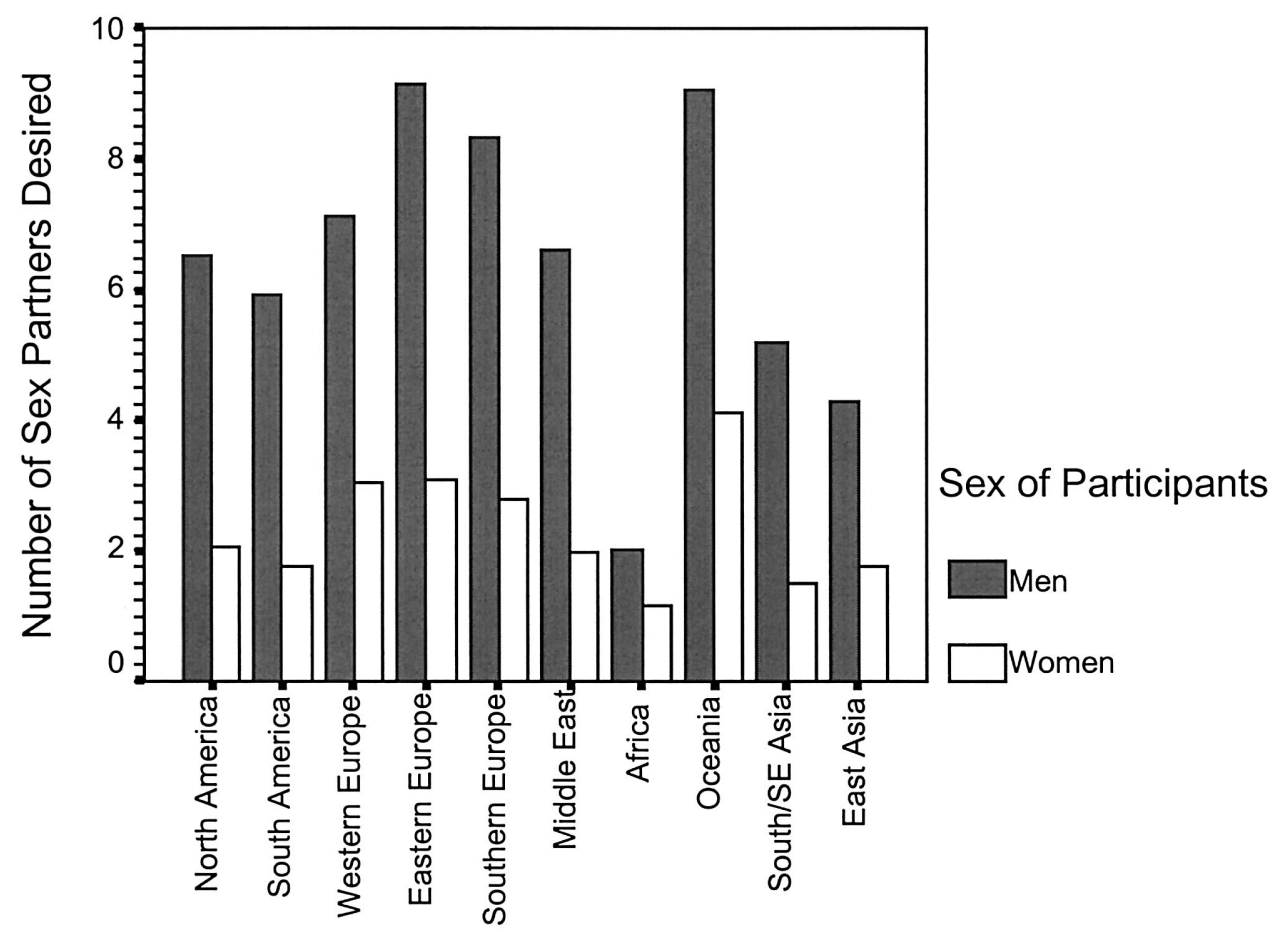

World Region

Figure 1. Mean number of sexual partners desired by men and women "in the next 30 years" across 10 world regions.

tests, in every case the Mann-Whitney $U$ tests indicated that men's and women's distributions were significantly different. ${ }^{2}$

\section{Sex Differences in the Desire for Sexual Variety: Categorical Analyses}

The mean-level, median-level, and distribution-based inferential statistics used thus far were restricted in some ways. Mean-level statistics can be unduly influenced by a few outliers, whereas median-level statistics sometimes belie important social consequences of distributional differences above the 50th percentile (Schmitt, Shackelford, \& Buss, 2001). In addition, even if median or Mann-Whitney $U$ distributional differences between men and women were deemed statistically significant, this would not necessarily address the issue of multiple versus monogamous mating desires. Women's medians, for example, could center near zero, whereas men's medians could center near one. In such a case, although men's and women's distributions would be considered significantly different, neither sex would be expressing a desire for sexual variety through multiple mating.

A more informative index of sex differences in desiring future sexual partners can be constructed by tabulating the number of participants who responded that they ideally desire "more than one" mating partner. For example, if people respond that they ideally desire more than one sex partner in the next month, they would be expressing desires for engaging in at least some form of multiple mating. Whether in the form of promiscuity or adultery (a point to be addressed later), desiring more than one sexual partner in the next month would be a clear index of an appetite for sexual variety. In addition, this categorization technique provides a good test of an alternate evolutionary theory (Miller \& Fishkin, 1997) that both men and women are designed for monogamous pair bonding and should tend to desire only one mating partner, at least

\footnotetext{
${ }^{2}$ W. C. Pedersen et al. (2002) sampled 266 college undergraduates from California and administered the Number of Partners measure originally used by Buss and Schmitt (1993). On the basis of the Maritz-Jarrett statistic (see Wilcox, 1987, 1996), W. C. Pedersen et al. concluded that men and women were not significantly different in the median number of sexual partners desired over time. However, the Maritz-Jarrett procedure may be unsuitable for comparing medians using the Number of Partners measure. This is because the Maritz-Jarrett is a ratio statistic very similar to the $z$ test or $t$ test, with median differences contained in the numerator and a denominator based on sample estimates of population variances around medians (see Wilcox, 1987, pp. 336-341). Because the MaritzJarrett statistic uses variance estimates, however, it is sensitive to distributional skew. Extreme values like those sometimes found in the Number of Partners measure tend to artificially inflate estimated variances-variances such as those in the denominator of the Maritz-Jarrett inferential statistic. As a result, the significance of median differences can be detrimentally affected by distributional skew when using the Maritz-Jarrett statistic. It seems peculiar to use medians instead of means because of heightened concerns with distributional skew, and then use an inferential statistical test that happens to be detrimentally susceptible to skew. The more common median test, as well as the more theoretically relevant distributional tests implemented earlier, are completely unaffected by extreme values. These more appropriate inferential statistics universally confirm that men and women significantly differ in the number of partners they desire over time.
} 
Table 4

Nonparametric Tests of Sex Differences in the Number of Sexual Partners Desired "in the Next Month" Across 10 World Regions

\begin{tabular}{|c|c|c|c|c|c|}
\hline \multirow[b]{2}{*}{ World region } & \multirow{2}{*}{$\frac{\text { Median test }}{\chi^{2}}$} & \multirow{2}{*}{$\begin{array}{c}\begin{array}{c}\text { Men's } \\
\text { ranking }\end{array} \\
M\end{array}$} & \multirow{2}{*}{$\begin{array}{c}\begin{array}{c}\text { Women's } \\
\text { ranking }\end{array} \\
M\end{array}$} & \multicolumn{2}{|c|}{ Mann-Whitney $U$ test } \\
\hline & & & & $U$ & $z$ \\
\hline North America & $367.18 * *$ & $2,152.31$ & $1,584.60$ & $1,029,152.00$ & $-17.79 * *$ \\
\hline South America & $78.21 * *$ & 360.74 & 250.94 & $28,429.50$ & $-8.64 * *$ \\
\hline Western Europe & $149.81 * *$ & $1,326.59$ & $1,063.95$ & $489,984.00$ & $-11.77 * *$ \\
\hline Eastern Europe & $214.00 * *$ & $1,247.52$ & 923.74 & $392,961.00$ & $-15.35^{* *}$ \\
\hline Southern Europe & $124.55^{* *}$ & 675.29 & 495.60 & $101,976.00$ & $-10.81 * *$ \\
\hline Middle East & $96.69 * *$ & 491.72 & 345.50 & $56,625.50$ & $-10.52 * *$ \\
\hline Africa & $38.05 * *$ & 484.01 & 356.37 & $63,007.50$ & $-8.49 * *$ \\
\hline Oceania & $59.24 * *$ & 459.09 & 346.49 & $54,233.50$ & $-8.09 * *$ \\
\hline South/Southeast Asia & $24.10^{* *}$ & 134.61 & 99.44 & $4,555.50$ & $-4.75 * *$ \\
\hline East Asia & $124.01 * *$ & 654.36 & 446.96 & $93,989.50$ & $-12.09 * *$ \\
\hline
\end{tabular}

$* * p<.001$

in the near future (see also W. C. Pedersen et al., 2002). If almost all participants desire multiple partners in the next month, however, this would support the view that humans are designed primarily for short-term mating (Barash \& Lipton, 2001). Consistent sex differences in desiring multiple partners, though, would support a pluralistic perspective on human mating.

For each world region, the percentage of male and female participants who reported desiring more than one sexual partner in the next month was tabulated. Sex differences in categorization were tested using the Kruskal-Wallis test, a nonparametric statistic evaluated on the chi-square distribution. As seen in Table 5, significantly more men than women desired more than one sexual partner within every major region of the world. For men, this categorical tabulation ranged from a low of $17.9 \%$ in East Asia to a high of $35.0 \%$ in South America. For most regions, about $25 \%$ of men wanted more than one sexual partner in the next month. Although these percentages fall short of considering most men to be seeking multiple mates in the next month, these findings provide an unmistakable indication that a large proportion of men (not simply a few deviants) ideally desire more than one mating partner in the near future.
It is crucial to remember, of course, that SST does not predict that most men will seek multiple mates. Rather, SST postulates that when men engage in short-term mating, they will tend to desire multiple mates and sexual variety more than when women engage in short-term mating. Thus, although the primary mode of mating in general appears to be for men to desire a single mate in the next month, when men express desires beyond long-term monogamy in the near future, those desires are centered on multiple short-term mates. This issue is extremely important for evaluating SST and is more fully addressed later.

In contrast to men's more-than-one profile in the next month, the tabulation for women ranged from a low of 2.6\% in East Asia to a high of $7.1 \%$ in Eastern Europe. Thus, relatively few women responded to the Number of Partners measure as though they desired sexual variety and multiple mates in the near future. Of importance, in every regional case significantly more men than women desired more than one sexual partner in the next month, as indicated down the right side of Table 5. Sex differences were also found in the percentage of men and women who desired more than one sexual partner "in the next 30 years." In most world regions, the percentage of men who desire more than one sexual partner in

Table 5

Sex Differences Using Categorical Analyses Based on the Percentage of Men and Women Who Desire More Than One Sexual Partner "in the Next Month" Across 10 World Regions

\begin{tabular}{lccr}
\hline \multicolumn{1}{c}{ World region } & $\begin{array}{c}\text { \% of men wanting } \\
\text { more than one } \\
\text { sexual partner }\end{array}$ & $\begin{array}{c}\text { \% of women wanting } \\
\text { more than one } \\
\text { sexual partner }\end{array}$ & $\chi^{2}$ \\
\hline North America & 23.1 & 2.9 & $369.27^{* * *}$ \\
South America & 35.0 & 6.1 & $79.92^{* *}$ \\
Western Europe & 22.6 & 5.5 & $151.36^{* *}$ \\
Eastern Europe & 31.7 & 7.1 & $215.55^{* *}$ \\
Southern Europe & 31.0 & 6.0 & $126.34^{* *}$ \\
Middle East & 33.1 & 5.9 & $98.30^{* *}$ \\
Africa & 18.2 & 4.2 & $39.32^{* *}$ \\
Oceania & 25.3 & 5.8 & $60.76^{* *}$ \\
South/Southeast Asia & 32.4 & 6.4 & $25.69^{* *}$ \\
East Asia & 17.9 & 2.6 & $71.28^{* *}$ \\
\hline
\end{tabular}

$* * p<.001$. 
the next 30 years approached the 50\% mark, a clear indication that more than a few outlying men are pursuing multiple mates. In every world region, significantly more men than women desired more than one sexual partner in the next 30 years (see Figure 2). Full analyses from all time intervals are available from the authors. Overall, these findings definitively document that sex differences in the desire for multiple sexual partners are culturally universal, at least across the varied regions of the ISDP.

\section{Sex Differences in the Desire for Sexual Variety: Demographic Statuses}

To further refine our understanding of men's and women's future mating desires, responses from the ISDP were used to categorize people in sociodemographic statuses (see Laumann, Gagnon, Michael, \& Michaels, 1994). For example, after collapsing all regions together, responses to the Confidential Personal Information scale of the ISDP were used to categorize individuals as either married ( $n=745 ; 343$ men, 402 women), living with someone ( $n=961 ; 384$ men, 577 women), dating one person exclusively ( $n=5,153 ; 1,814$ men, 3,339 women), or currently not involved with anyone ( $n=4,941 ; 2,304$ men, 2,637 women). As detailed at the top of Table 6 , within each current relationship status, men were much more likely than women to desire more than one sexual partner in the next month. In the case of married participants, this directly implies that men (12.8\%) are more likely than women $(3.5 \%)$ to desire short-term mates in the form of extramarital relationships. In the case of those participants living with someone or dating one person exclusively, sex differences in unfaithful forms of short-term mating are also implicated. In the case of those not currently involved with anyone, the current findings confirm that sex differences in short-term mating persist outside the context of adultery-such as with men's greater tendency toward general sexual promiscuity (Eysenck, 1976; Simpson \& Gangestad, 1991; Wright \& Reise, 1997).

The participants' responses to the Confidential Personal Information scale of the ISDP were also used to categorize individuals as either heterosexual ( $n=11,896 ; 4,995$ men, 6,901 women), homosexual ( $n=276 ; 148$ men, 128 women), or bisexual $(n=$ $315 ; 103$ men, 212 women). As listed in Table 6, within each sexual orientation status, men desired significantly larger numbers of sexual partners in the next month than women did. This evidence directly supports the evolutionary psychology view that men's evolved short-term desires are a modular cause of the desire for large numbers of partners (Kenrick, Sadalla, \& Keefe, 1998). This modularity explanation is supported because, regardless of whether men or women are the targets of sexual desire, it is the sexual psychology of the desirer (i.e., men's short-term, "in the next month" mating psychology) that is most closely associated with the desire for more than one sexual partner (see also Bailey, Gaulin, Agyei, \& Gladue, 1994).

The Short-Term Seeking scale from the ISDP, adapted from Buss and Schmitt (1993), was used to classify individuals' levels of currently seeking a short-term mate. Each participant was asked to respond on a 1-7 scale (with $1=$ not at all, $4=$ moderately, and

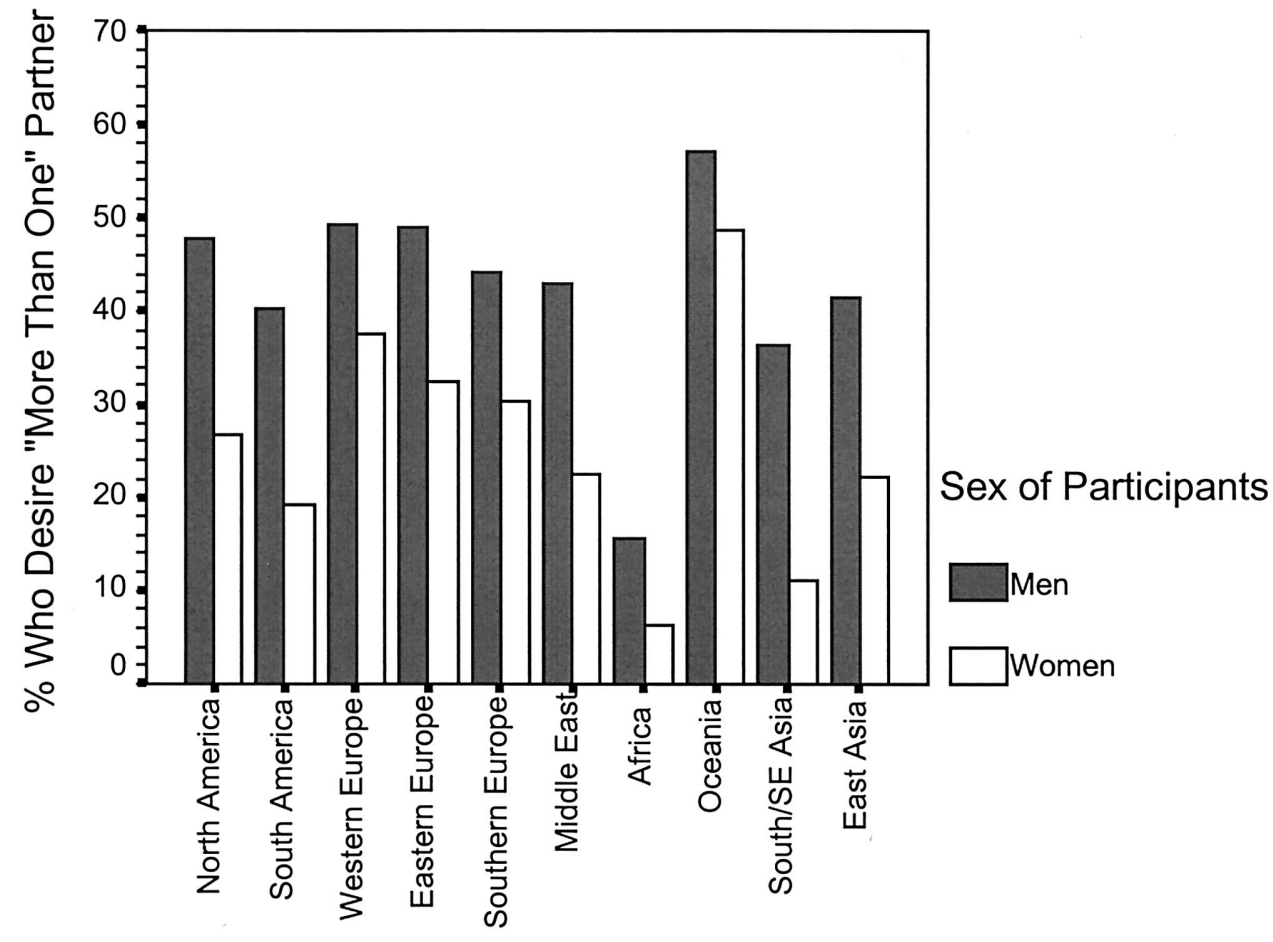

\section{World Region}

Figure 2. Percentage of men and women who desire more than one sexual partner "in the next 30 years" across 10 world regions. 
Table 6

Sex Differences Using Categorical Analyses Based on the Percentage of Men and Women

Across the World Who Desire More Than One Sexual Partner "in the Next Month," as Reported Across Current Relationship Status, Sexual Orientation Status, and Whether They Were Currently Seeking Short-Term Mates

\begin{tabular}{lccr}
\hline \multicolumn{1}{c}{ Status } & $\begin{array}{c}\text { \% of men wanting } \\
\text { more than one } \\
\text { sexual partner }\end{array}$ & $\begin{array}{c}\text { \% of women wanting } \\
\text { more than one } \\
\text { sexual partner }\end{array}$ & $\chi^{2}$ \\
\hline Current relationship status & & & \\
$\quad$ Married & 12.8 & 3.5 & $22.49^{* *}$ \\
$\quad$ Cohabiting & 18.2 & 2.4 & $72.11^{* *}$ \\
$\quad$ Dating one person exclusively & 19.0 & 2.7 & $398.20^{* *}$ \\
$\quad$ Not currently involved & 28.6 & 6.2 & $443.69^{* *}$ \\
Sexual orientation status & 25.4 & 4.4 & $1,109.83^{* *}$ \\
$\quad$ Heterosexual & 29.1 & 5.5 & $25.65^{* *}$ \\
$\quad$ Homosexual & 30.1 & 15.6 & $9.01^{*}$ \\
$\quad$ Bisexual & 53.5 & 18.7 & $130.02^{* *}$ \\
Short-term mate seeking status & 35.2 & 9.7 & $358.13^{* *}$ \\
$\quad$ Strongly seeking & 10.5 & 2.0 & $286.81^{* *}$ \\
$\quad$ Moderately seeking & & & \\
$\quad$ Not currently seeking & & & \\
\hline
\end{tabular}

Note. For short-term mate seeking status, strongly seeking was defined as 6 or above on a 1-7 scale of short-term mate seeking (Buss \& Schmitt, 1993); moderately seeking corresponded to ratings between 3 and 5; and ratings of 1 or 2 were defined as not currently seeking a short-term mate.

$* p<.01$. ** $p<.001$.

7 = strongly) the degree to which they were actively seeking short-term mates. Responses were coded so that those individuals scoring a 6 or a 7 were considered strongly seeking short-term mates ( $n=1,180 ; 789$ men, 391 women). Those scoring a $3-5$ were considered moderately seeking a short-term mate $(n=3,904$; 2,038 men, 1,866 women). Finally, those participants scoring a 1 or 2 were considered not seeking a short-term mate $(n=8,031$; 2,697 men, 5,334 women). Across all participants, men tend to score higher than women in seeking short-term mates, $t(13,087)=28.23, p<.001, d=0.49$. As listed in the bottom of Table 6, within each short-term mate seeking status, men were significantly more likely than women to be seeking more than one sexual partner in the next month.

This evidence provides the clearest support for the evolutionary psychology view that men's evolved short-term mating psychology is likely related to the desire for large numbers of partners. Why? Because even those women who reported that they were strongly seeking a short-term mate did not overwhelmingly desire more than one sexual partner in the next month. Less than $20 \%$ of these women desired more than one partner in the next month, about the same level of multiple-partner seeking evidenced by men who were currently dating one person exclusively or living with someone. Among those men who were strongly seeking a shortterm mate, in contrast, over $50 \%$ desired more than one sexual partner in the next month. This percentage increased to $69 \%$ in the next 6 months, and $75 \%$ in the next year. For women, the percentage increases were only marginal over time. When men actively pursue a short-term sexual strategy, therefore, they appear strongly motivated by the desire for multiple mating partners. For women, multiple mating is not as strongly connected with their psychology of short-term mating (Buss \& Schmitt, 1993; Gangestad \& Simpson, 2000). In sum, these ISDP findings provide strong support for SST and other theories of human mating that postulate men and women fundamentally differ in their short-term mating psychology, particularly in the basic desire for sexual variety.

\section{Sex Differences in Needing Time Before Consenting to Sex}

In addition to men's more potent desire for sexual variety, SST postulated that men would be quicker to consent to sex than women would after knowing a potential mate for various periods of time. In their original research, Buss and Schmitt (1993) found that the average man would consent to sex after knowing a woman for about a week, whereas the average woman reported that she would not consent to sex until 6 months had elapsed in knowing the potential partner. The intermediate " 1 -month" time interval-a special focus in the previous Number of Partners analyses-was also of particular interest to Buss and Schmitt because it displayed a valence shift, with the average man viewing sex as likely $(M=1.11)$ and the average woman viewing sex as unlikely $(M=$ -1.50) after knowing someone for 1 month (based on a scale ranging from $+3=$ definitely would have sex to $-3=$ definitely would not have sex). Recently, Schmitt, Shackelford, Duntley et al. (2001) replicated Buss and Schmitt's findings in a larger sample from the United States. They documented that American men were likely to consent to sex, whereas American women were unlikely to consent to sex, after knowing a potential mating partner for brief periods of time, including the special "1-month" time interval.

In the current ISDP investigation, men and women differed in the likelihood of consenting to sex after knowing someone for " 1 month" across all major regions of the world (see Table 7). Within the region of North America, for instance, the average man reported a 0.63 likelihood of consenting to sex, whereas the average woman reported a -1.14 level, $t(3642)=25.32, p<.001$. According to Cohen's $d$ statistic, the magnitude of the difference between North American men and women $(d=0.80)$ was large in size (Cohen, 1988). This sex difference was slightly larger in South America and other regions, though the effect was only moderate in size in the African world region $(d=0.48)$. Overall, men's mean levels of consenting to sex after knowing a potential 
Table 7

Mean-Level Sex Differences in Consenting to Sex After Knowing Someone for "1 Month" Across 10 World Regions

\begin{tabular}{|c|c|c|c|c|c|c|}
\hline \multirow[b]{2}{*}{ World region } & \multicolumn{2}{|c|}{ Men } & \multicolumn{2}{|c|}{ Women } & \multirow[b]{2}{*}{$t$} & \multirow[b]{2}{*}{$d$} \\
\hline & $M$ & $S D$ & $M$ & $S D$ & & \\
\hline North America & 0.63 & 2.10 & -1.14 & 1.99 & $25.32 * *$ & 0.80 \\
\hline South America & 1.35 & 1.89 & -1.11 & 2.05 & $16.98 * *$ & 1.06 \\
\hline Western Europe & 1.28 & 1.90 & 0.17 & 2.09 & $14.01 * *$ & 0.53 \\
\hline Eastern Europe & 1.00 & 1.98 & -0.57 & 2.07 & $18.83 * *$ & 0.72 \\
\hline Southern Europe & 0.87 & 2.08 & -0.91 & 2.08 & $14.70 * *$ & 0.79 \\
\hline Middle East & 1.26 & 1.99 & -0.96 & 2.19 & $16.50 * *$ & 0.94 \\
\hline Africa & -1.00 & 2.20 & -1.99 & 1.75 & $7.47 * *$ & 0.48 \\
\hline Oceania & 1.30 & 1.92 & -0.13 & 2.16 & $10.02 * *$ & 0.66 \\
\hline South/Southeast Asia & 0.30 & 2.11 & -2.33 & 1.46 & $14.54 * *$ & 1.20 \\
\hline East Asia & -0.52 & 2.06 & -2.13 & 1.47 & $15.22 * *$ & 0.82 \\
\hline
\end{tabular}

mate for 1 month were significantly higher than women's mean levels across all world regions, $F(1,15126)=1,887.73, p<.001$. The effect of world region was also significant, $F(9,15126)=$ $174.91, p<.001$, as was the interaction of sex and world region, $F(9,15126)=16.75, p<.001$.

Even though we observed that sex differences in the likelihood of consenting to sex after knowing someone for " 1 month" were culturally universal across the regions of the ISDP, there were two notable deviations from the general pattern uncovered in previous studies (Buss \& Schmitt, 1993). First, women from Western Europe and Oceania were very close to being positive toward con- senting to sex at the "1-month" time interval (see Figure 3). In all other world regions, women scored more negatively at that time interval, reporting that they viewed it as rather unlikely they would consent to sex after knowing someone for a single month. When looking at the "1-week" time interval from the Time Known measure, however, it was clear that both Western European and Oceanic men remained positive toward consenting to sex after 1 week, whereas women from these regions were decidedly negative toward consenting to sex after 1 week. It appeared, therefore, that the key temporal period showing a valence shift between the sexes-a difference where men are positive and women are neg-

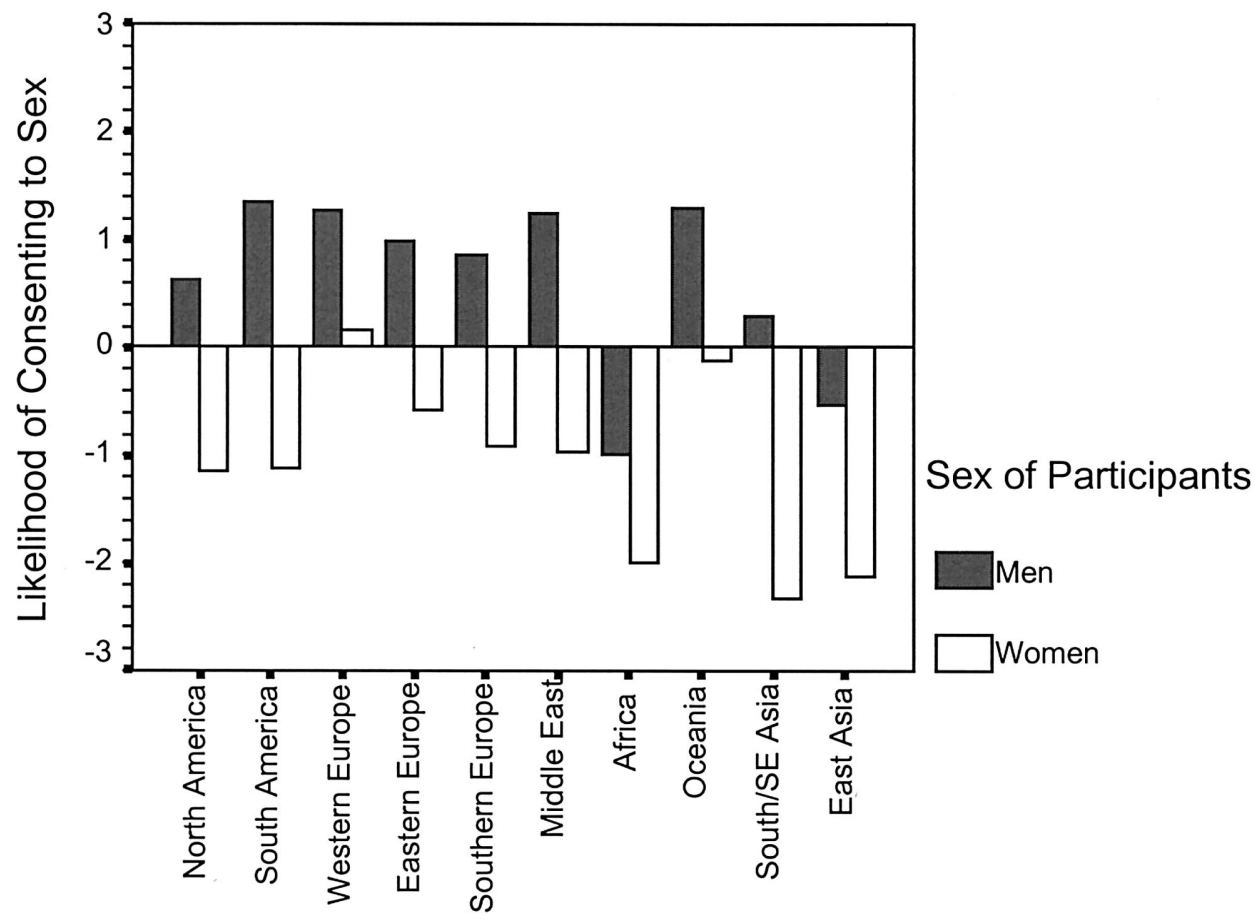

\section{World Region}

Figure 3. Mean likelihood of consenting to sex after knowing someone for " 1 month" across 10 world regions. 
Table 8

Mean-Level Sex Differences in Short-Term Mate Seeking Across 10 World Regions

\begin{tabular}{|c|c|c|c|c|c|c|}
\hline \multirow[b]{2}{*}{ World region } & \multicolumn{2}{|c|}{ Men } & \multicolumn{2}{|c|}{ Women } & \multirow[b]{2}{*}{$t$} & \multirow[b]{2}{*}{$d$} \\
\hline & $M$ & $S D$ & $M$ & $S D$ & & \\
\hline North America & 3.08 & 1.97 & 2.23 & 1.68 & $13.84 * *$ & 0.46 \\
\hline South America & 3.07 & 1.96 & 1.88 & 1.37 & $9.80^{* *}$ & 0.67 \\
\hline Western Europe & 2.54 & 1.87 & 1.91 & 1.49 & $9.95 * *$ & 0.38 \\
\hline Eastern Europe & 2.79 & 1.90 & 1.92 & 1.52 & $13.18^{* *}$ & 0.50 \\
\hline Southern Europe & 3.30 & 2.10 & 2.13 & 1.58 & $11.24 * *$ & 0.62 \\
\hline Middle East & 3.17 & 2.09 & 1.96 & 1.52 & $10.50^{* *}$ & 0.63 \\
\hline Africa & 2.75 & 1.98 & 1.85 & 1.54 & $7.61 * *$ & 0.49 \\
\hline Oceania & 2.98 & 1.96 & 2.40 & 1.73 & $4.66^{* *}$ & 0.31 \\
\hline South/Southeast Asia & 3.19 & 1.91 & 2.17 & 1.47 & $6.56^{* *}$ & 0.59 \\
\hline East Asia & 3.09 & 1.82 & 2.48 & 1.63 & $5.99 * *$ & 0.35 \\
\hline
\end{tabular}

$* * p<.001$.

ative toward consenting to sex-was slightly displaced in Western Europe and Oceania toward the "1-week" time interval. Although beyond the limited sex-difference scope of this article, the potential causes behind this basic cultural displacement may include evolutionary, religious, and social-role factors (see Schmitt, 2003c). For example, more liberal or "promiscuous-oriented" sexual attitudes across cultures tend to be related to female-biased sex ratios, low fertility rates, atheism, and gender-egalitarian political systems, all of which appear to play some role in the current ISDP findings (see also Schmitt et al., in press).

A second regional deviation from previous research was that men from Africa and East Asia expressed negative likelihoods of consenting to sex at the "1-month" time period. For East Asian men, the average response reached a positive level at the " 3 month" time interval, a slight shift toward conservative sexual attitudes that potentially may be related to the male-biased sex ratios in East Asia (Guttentag \& Secord, 1983; F. A. Pedersen, 1991; Schmitt, 2003c). For African men, however, the average male was not positive toward consenting to sex until the "1-year" time interval had elapsed. As mentioned earlier, the reduced tendencies toward short-term mating in Africa may be influenced by the widespread rate of HIV/AIDS in several of the African cultures sampled by the ISDP (Schmitt et al., in press).

Despite these interesting within-sex regional variations, it is important to note that comparing general mean levels (whether among men or women) across individual cultures can be an extremely problematic enterprise (Heine, Lehman, Peng, \& Greenholtz, 2002). The focus of the current study, in contrast, was on investigating the significance and magnitude of sex differences across cultures. Regardless of a culture's general sexual attitudes, we found clear and unequivocal evidence that the Time Known sex differences originally documented by Buss and Schmitt (1993) were robust across the geographically diverse samples of the ISDP. It seems reasonable to conclude, on the basis of this new evidence of universal sex differences, that human males generally require less time before consenting to sex than human females do. The current findings, therefore, may be viewed as providing crosscultural evidentiary support for the hypothesis that men's evolved sexual desires, designed in the short term to lead to quick sex and to quantitatively increase men's total numbers of mating partners, are distinct from women's more qualitative desires of short-term mating (Gangestad, 2001).

\section{Sex Differences in Actively Seeking Short-Term Mates}

According to SST, men should actively seek short-term mates more than women do. Again, it is not that women are expected to never seek short-term mateships. Women are expected by SST and other evolutionary theories to seek men as short-term mates, especially those men with superior resources, physical attributes, or genetic quality (Buss \& Schmitt, 1993; Gangestad \& Simpson, 2000). However, because men's short-term psychology is specialized for obtaining large numbers of partners and requiring little time before consenting to sex, Buss and Schmitt (1993) predicted that men would more actively seek short-term mates than women. That is, men as-a-whole would tend to spend more effort on short-term mating because their strategy is based on attracting a larger number of sex partners and a more vigilant eagerness to engage in short-term sex.

To test this prediction, men's and women's mean levels on the Short-Term Seeking measure developed by Buss and Schmitt (1993) were compared across all 10 ISDP world regions. As seen in Table 8 , men were significantly higher in seeking short-term mates than women across all world regions, $F(1,15658)=710.05$, $p<.001$. Within the region of North America, for instance, the average man reported a 3.08 level of seeking short-term mates, whereas the average woman reported a 2.23 level, $t(3631)=13.84, p<.001$. This sex difference was somewhat larger in South America and some other regions, though the effect was only moderate in Oceania and East Asia. Overall, the main effect of world region was significant, $F(9,15658)=20.99, p<$ .001 , as was the interaction of sex and world region, $F(9$, $15658)=5.60, p<.001 .^{3}$

An additional avenue for evaluating sex differences in shortterm mate seeking is to compare the relative percentages of men versus women who rate above 1.0 on the Short-Term Seeking measure developed by Buss and Schmitt (1993). This relative percentage statistic indicates the degree to which men and women are in any way seeking short-term mates. On empirical examina-

\footnotetext{
${ }^{3}$ On the basis of post hoc analyses (e.g., Tukey's HSD), the main effect of world region appeared driven by higher levels of short-term seeking in East Asia and lower levels in Western Europe. The interaction effect appeared driven primarily by larger sex differences in South America and smaller sex differences in Oceania.
} 
tion, significantly more men than women scored above 1.0 on this scale across all world regions, including participants from North America (65.2\% of men, $45.4 \%$ of women), $\chi^{2}(1, N=3,633)=$ 132.51, $p<.001$, South America $(65.1 \%$ of men, $36.3 \%$ of women $), \chi^{2}(1, N=757)=62.26, p<.001$, Western Europe (51.8\% of men, $36.0 \%$ of women), $\chi^{2}(1, N=2,865)=68.50, p<$ .001 , Eastern Europe (58.4\% of men, $34.8 \%$ of women), $\chi^{2}(1$, $N=2,696)=148.95, p<.001$, Southern Europe $(66.5 \%$ of men, $44.1 \%$ of women $), \chi^{2}(1, N=1,287)=60.44, p<.001$, Middle East $(62.3 \%$ of men, $37.2 \%$ of women $), \chi^{2}(1, N=$ $999)=62.92, p<.001$, Africa (54.3\% of men, $28.6 \%$ of women), $\chi^{2}(1, N=947)=62.33, p<.001$, Oceania $(61.5 \%$ of men, $49.4 \%$ of women), $\chi^{2}(1, N=891)=12.77, p<.001$, South/Southeast Asia (69.9\% of men, $49.6 \%$ of women), $\chi^{2}(1, N=466)=19.13$, $p<.001$, and East Asia (73.4\% of men, $58.3 \%$ of women), $\chi^{2}(1$, $N=1,137)=28.47, p<.001$. Thus, across every region of the ISDP, significantly more men than women reported seeking shortterm mates, with a majority of men within each world region reporting that they were at least somewhat seeking a short-term mate.

A limitation of the Short-Term Seeking measure developed by Buss and Schmitt (1993) is that it does not specify the precise type or form of short-term mating desired by participants. One way to address this limitation is to look at short-term mate seeking across the demographic variable of current relationship status. For example, by looking only at those participants who are currently married, one can assess the degree to which men and women actively seek short-term mates in the form of marital infidelity. Looking at the short-term desires of those not currently in a romantic relationship, in contrast, can provide an assessment of men's and women's desires for short-term relationships more generally (see Schmitt, 2002b, for a more complete discussion of the differences between the psychology of infidelity and general promiscuity). As seen in Table 9, men were significantly more likely to have actively sought short-term mates of all types across all relationship statuses. Among married participants, for example, nearly one quarter of men $(24.5 \%)$ and one tenth of women $(10.4 \%)$ were at least somewhat active in seeking short-term mates (i.e., they scored above 1.0 on the Short-Term Seeking measure), a significant difference, $\chi^{2}(1, N=958)=33.86, p<.001$. This sex difference also was evident when comparing married men's $(M=1.72)$ and married women's $(M=1.27)$ mean levels of short-term mate seeking, $t(956)=5.61, p<.001, d=0.36$. These findings provided a relatively unambiguous indication that men actively seek short-term mates for adulterous relationships more than women do.
These findings correspond closely to actual rates of marital infidelity reported in other survey studies. For example, according to Wiederman (1997), approximately $24 \%$ of American men and $12 \%$ of American women have engaged in extramarital sex. Evidence from those who currently live with a partner and from those who are exclusively dating one person further bolster the basic contention that men more actively seek adulterous short-term mateships than women do. Finally, a majority of men and women in the ISDP who were not currently in a romantic relationship reported seeking short-term mates, with significantly more men than women displaying this proclivity toward general promiscuity. Regardless of whether sex differences in short-term mate seeking were evaluated using categorical or dimensional analyses, men in every type of relationship (including no relationship) were significantly more likely than women to have actively sought short-term mates.

In sum, the Short-Term Seeking findings of Buss and Schmitt (1993) were replicated and extended across a large and geographically diverse sample of participants. At this point, it appears highly likely that men spend more reproductive effort seeking short-term mates than women do. Most important, among modern evolutionary theories of human mating it seems that theories such as SST-theories that hypothesize sex differences in the evolved design of short-term mating-provide the best account of the universal sex differences observed in the ISDP.

\section{Discussion}

In this article, evidence from the ISDP - a cross-cultural survey of over 16,000 people from 10 major regions of the worlddocuments that sex differences in short-term mating desires, particularly the desire for sexual variety, are cross-culturally universal. This is true regardless of the statistical techniques used to evaluate them. This is true regardless of the participant's current relationship status or sexual orientation. Married or single, heterosexual or homosexual-men consistently desire larger numbers of sexual partners than women do. Most important, among those men and women who are actively pursuing short-term mates, over $50 \%$ of men (but less than $20 \%$ of women) desire more than one sexual partner in the next month. This critical empirical finding confirms that men's short-term sexual strategy is differentially rooted in the desire for multiple partners (Buss \& Schmitt, 1993).

The present empirical findings have strong theoretical implications. These findings render theories that argue humans should not desire sexual variety because both men and women are designed only for long-term mating (e.g., Hazan \& Diamond, 2000; Miller

Table 9

Sex Differences in Short-Term Mate Seeking Using Categorical and Dimensional Analyses as Reported Across Current Relationship Status

\begin{tabular}{|c|c|c|c|c|c|c|c|c|c|}
\hline \multirow[b]{2}{*}{ Current relationship status } & \multicolumn{3}{|c|}{$\begin{array}{l}\% \text { who report above } 1.0 \text { on } \\
\text { short-term seeking measure }\end{array}$} & \multicolumn{2}{|c|}{ Men } & \multicolumn{2}{|c|}{ Women } & \multirow[b]{2}{*}{$t$} & \multirow[b]{2}{*}{$d$} \\
\hline & Men & Women & $\chi^{2}$ & $M$ & $S D$ & $M$ & $S D$ & & \\
\hline Married & 24.5 & 10.4 & $33.86^{* *}$ & 1.72 & 1.51 & 1.27 & 0.94 & $5.61 * *$ & 0.36 \\
\hline Cohabiting & 38.8 & 16.2 & $71.01 * *$ & 2.05 & 1.63 & 1.38 & 1.01 & $8.49^{* *}$ & 0.51 \\
\hline Dating one person exclusively & 45.2 & 26.8 & $201.09 * *$ & 2.27 & 1.73 & 1.61 & 1.20 & $17.07 * *$ & 0.46 \\
\hline Not currently involved & 79.3 & 64.0 & $161.20 * *$ & 3.57 & 1.89 & 2.77 & 1.75 & $16.70^{* *}$ & 0.43 \\
\hline
\end{tabular}

$* * p<.001$. 
\& Fishkin, 1997; W. C. Pedersen et al., 2002) or short-term mating (e.g., Hrdy, 1981) as unlikely to be correct. In contrast, theories that argue men and women are psychologically designed, in part, for short-term mating (e.g., Gangestad \& Simpson, 2000) are more likely to be correct given our ISDP findings. Finally, theories that hypothesize men and women to differ in their mating psychology because of men's evolved short-term preference for multiple partners are, based on the present findings, much more likely to be correct than alternative theories (see also Schmitt, Shackelford, \& Buss, 2001).

In the future, continued efforts to deny these well-documented sex differences in the desire for sexual variety may come at significant cost. For example, among the most potent risk factors for contracting HIV/AIDS is having sex with multiple partners (Hoyle, Fejfar, \& Miller, 2000; Mills et al., 1998). Although reducing the desire for sexual variety is a key objective of many HIV prevention strategies, it has proven extremely resistant to change (Weinhardt, Carey, Johnson, \& Bickham, 1999). The most effective strategies have tended to be those that use sex-specific methods of intervention (Mize, Robinson, Bockting, \& Scheltema, 2002). To continue to assert that men and women do not differ in the desire for sexual variety, therefore, may serve to derail progress in investigating the circumstances under which the desire for sexual variety gets translated into actual high-risk behavior, and in developing sex-specific interventions that reduce the negative consequences of multiple-mating desires when they occur.

\section{Converging Lines of Evidence: Beyond the Limitations of Self-Report}

When Buss and Schmitt (1993) first outlined SST, they reviewed previous research and provided a limited amount of original empirical support for their theory, primarily from self-report surveys involving American undergraduates (for a critique, see Miller, Putcha-Bhagavatula, \& Pedersen, 2002). Since then, numerous survey and meta-analytic studies have confirmed many of the major tenets of SST (e.g., Landolt, Lalumiere, \& Quinsey, 1995; Oliver \& Hyde, 1993; Regan, 1998a, 1998b; Regan \& Berscheid, 1997; Scheib, 1997; Schmitt, 2002a; Schmitt \& Buss, 1996, 2001; Shackelford \& Buss, 1997). Some studies have replicated or confirmed SST-related findings using national, crosscultural, or multicultural samples (Bailey, Kirk, Zhu, Dunne, \& Martin, 2000; Schmitt et al., in press; Sprecher, Sullivan, \& Hatfield, 1994). Other investigators have used more rigorous nonsurvey techniques - including experimental, behavioral, and naturalistic methodologies-to validate key SST hypotheses (Hassebrauck, 1998; Kenrick, Neuberg, Zierk, \& Krones, 1994; Malamuth, 1996; Salmon \& Symons, 2001; Schmitt, Couden, \& Baker, 2001; Simpson, Gangestad, Christensen, \& Leck, 1999; Speed \& Gangestad, 1997; Wiederman \& Dubois, 1998).

These latter studies are particularly important because they suggest that the present findings are not simply artifacts of selfreport methodologies. It is true that self-reported sexual behaviors are subject to significant distortions and biases (Wiederman, 1997). Furthermore, our ISDP samples were clearly not representative of each nation as a whole. However, there are three reasons for having a reasonable degree of confidence in the generalizability of the present findings. First, the current ISDP results converge with a large network of nonsurvey evidence that men and women possess specially designed short-term mating psychologies. For example, the present findings converge with recent experimental, psychophysiological, and anthropometric studies that suggest men and women have distinct adaptations to short-term mating (see Baker \& Bellis, 1995; Gangestad, 2001; Gangestad \& Simpson, 2000; Schmitt, 2003b; Schmitt, Couden, \& Baker, 2001). Second, previous studies looking at more representative samples from non-Western nations have confirmed several SST hypotheses (e.g., Knodel, Low, Saengtienchai, \& Lucas, 1997; Walter, 1997). Indeed, over the past 10 years SST has repeatedly proven an effective heuristic for generating testable hypotheses, and for integrating new methodologically diverse findings, concerning the temporally distinct psychology of romantic desire and sexual behavior (see also Buss, 1997; Schmitt, Shackelford, \& Buss, 2001). Third, the present results mesh with a wide range of empirical findings from across the social sciences, including sex differences in motivations and prevalence of extramarital mating (Laumann et al., 1994; Wiederman, 1997), sex differences in the quality and quantity of sexual fantasies (Leitenberg \& Henning, 1995), sex differences in the quality and quantity of pornography consumption (Malamuth, 1996), sex differences in the motivations for and use of prostitution (Bess \& Janus, 1976; Burley \& Symanski, 1981), sex differences in the willingness to have sex with strangers (Clark, 1990; Clark \& Hatfield, 1989), and fundamental sex differences between the short-term mating psychology of gay males and lesbians (Blumstein \& Schwartz, 1983). The present ISDP findings on the universality of sex differences in the desire for sexual variety, therefore, should be taken as an incremental addition to the accumulating body of evidence that men and women differ in their evolved psychology of short-term mating.

\section{SST: Addressing Some Misconceptions}

One of the defining features of SST-a feature that distinguished SST from previous evolutionary theories of human mating-was its special focus on within-sex variability (Buss \& Schmitt, 1993). In contrast to parental investment theory's (Trivers, 1972) emphasis on sex differences, SST postulated that within men and within women there exist psychological adaptations for both long-term and short-term mating. SST viewed human males and females as functionally designed to sometimes pursue longterm mates (i.e., marital partners), and at other times to pursue short-term mates (i.e., one-night stands). Of importance, when men and women pursue short-term mates, SST predicted that their romantic desires and attraction behaviors would strategically shift compared with when they pursued long-term mates (Schmitt \& Buss, 1996). Thus, a special focus of SST was on the important psychological sensitivities within men and within women to the temporal continuum of human mating.

In addition to temporal context differences, SST postulated that evolved mating psychologies sometimes display between-sex differences. This was thought to be especially true within the context of short-term mating, where men and women have likely faced very different evolutionary pressures throughout our ancestral past. For example, because the primary constraint to male reproductive success in foraging societies would have been gaining sexual access to large numbers of fertile women (Symons, 1979), SST postulated that men over evolutionary history would have benefited reproductively by increasing the number of their short-term sexual partners (i.e., Prediction 2 from Hypothesis 1 of SST; Buss \& Schmitt, 1993, p. 210). In contrast, it was hypothesized that 
women in our evolutionary past would have received little reproductive benefit simply by increasing the number of people with whom they have sex. For women, the quality of their short-term mating partners would have had more of an effect on their reproductive success than the quantity of their partners (see also Ellis, 1992; Gangestad \& Thornhill, 1997). Thus, a second special focus of SST was on between-sex differences in romantic desire and behavior, particularly those between-sex differences that occur within the temporal context of short-term mating.

Despite SST's special focus on understanding sex differences within either short-term or long-term mating contexts, it has occasionally been misconstrued as a theory concerning only general differences between male (i.e., short-term) versus female (i.e., long-term) mating psychology (e.g., see Hazan \& Diamond, 2000, pp. 186-187). This conceptual conflation of sex and temporal context is a fundamental misinterpretation of SST's basic premises. Instead of dichotomous depictions of "male/short-term" versus "female/long-term" mating psychologies, SST theorized that key male-female differences take place interactively within the temporal contexts of either short-term or long-term mating. For example, SST's Prediction 2 from Hypothesis 1 -the prediction that men would desire more numerous mating partners than women-was a prediction concerning sex differences due to the special nature of men's short-term mating psychology, not a prediction concerning men and women regardless of temporal context (see also Schmitt, Shackelford, \& Buss, 2001).

One explanation for why some continue to misunderstand SST in this manner may reside in their underappreciation of the potential adaptive value that short-term mating affords women (see Barash \& Lipton, 2001; Gangestad \& Simpson, 1990; Scheib, 1997). This conceptual failure may, in turn, incite some to adhere to the erroneous view that SST characterizes women as solely interested in long-term mating, whereas men alone can gain from short-term mating. SST does not postulate that women are limited to long-term mating. SST delineated numerous benefits that can accrue to women from pursuing a short-term sexual strategy (see also Gangestad, 2001; Greiling \& Buss, 2000; Hrdy, 1981), as well as the important benefits to men of pursuing long-term mating strategies (Buss \& Schmitt, 1993). It is extremely unfortunate that, nearly 10 years after the publication of SST, some continue to misconstrue SST's fundamental assertion that both men and women can reproductively benefit from pursuing long-term and short-term sexual strategies.

\section{A Key Sex Difference: The Desire for Sexual Variety When Short-Term Mating}

Although both men and women are adaptively designed for short-term mating, SST makes distinctions between the way men and women are expected to strategically pursue short-term mateships (Schmitt \& Buss, 1996). As noted earlier, one of the more striking strategic differences in the pursuit of short-term relationships stems from men's evolved short-term desire for large numbers of sexual partners. It was because of this hypothesized desire that Prediction 2 from SST stated, "For any given period of time (e.g., a month, a year, a decade, or a lifetime), men will desire a larger number of mates than will women" (Buss \& Schmitt, 1993, p. 210). To evaluate whether men really desire more sexual partners than women over time, Buss and Schmitt (1993) developed a Number of Partners self-report measure. This measure was de- signed to assess the extent to which men and women differed in the ideal number of sex partners they would like to have over various time periods-ranging from "in the next month" to "in your remaining lifetime." In every case, men preferred significantly larger numbers of sex partners than women.

The current ISDP findings suggest that this sex difference may be a cultural universal. Men and women differ in the number of partners they desire over various time intervals, regardless of whether they are from North America, South America, Western Europe, Eastern Europe, Southern Europe, Middle East, Africa, Oceania, South/Southeast Asia, or East Asia. Moreover, sex differences in the number of partners desired were significant regardless of whether means, medians, or other indexes of "typicality" were examined (see also Schmitt, Shackelford, Duntley et al., 2001). Men were shown to desire larger numbers of sexual partners than women in every major region of the world regardless of relationship status, sexual orientation, or whether the person is "actively seeking" short-term mates.

These findings provide strong support for the evolutionary view that men possess psychological adaptations that motivate a desire for large numbers of partners when pursuing a short-term mating strategy (Buss \& Schmitt, 1993). These ISDP findings also appear to refute alternate hypotheses that men and women are designed for a singular mating strategy, whether based solely on long-term monogamy or short-term promiscuity. Still, there remain viable alternative explanations for the current findings.

\section{Alternate Explanations for Universality of Sex Differences in Sexual Desire}

Despite the present evidence that sex differences in the desire for sexual variety appear culturally universal, it is important to note that alternate nonevolutionary explanations of these findings may exist. For example, the robust sex differences observed in the ISDP may be due to culturally universal features of gender socialization and social-role stereotyping (e.g., Eagly, 1987). Men may desire sexual variety more than women do because men universally experience developmental forces such as more often observing high-status men preferring sexual variety. Short-term mating with multiple partners may also be central to every world region's view of masculinity. Still, these proximate explanations would only be true alternatives to an evolutionary perspective on universality if the same socialization processes somehow arose in all cultures independently, and for nonbiological reasons. Such random pancultural development, although possible, is extremely unlikely (Cronk, 1999). Even if pancultural socialization practices associated with sex differences in basic mating tendencies were found, ultimate-evolutionary questions would remain as to why men would universally experience this form of socialization, why cultures would universally define masculinity in this way, and why sex roles would exist in the first place.

Eagly and Wood (1999) have suggested that sex roles are primarily responsible for many differences between men's and women's mating strategies, and that the sex roles themselves are derived from evolved physical and reproductive differences between men and women. A key implication of their theory is that men and women may not have evolved differences in the psychology of short-term mating, per se, but instead respond in a more flexible way to the intensity of gender norms and economic divisions of labor that happen to be present in a given local culture. Of 
importance, when sex roles are more egalitarian because of women's increased politico-economic status, Eagly and Wood predicted that men and women would be more similar in mating strategies. In other words, as women gain equal power, their desires for sexual variety may become identical to men's desires. As noted elsewhere (Schmitt et al., in press), this is not always the case. Men tend to show signs of being more oriented to short-term mating than women even in highly egalitarian cultures. Still, the magnitude of sex differences in the desire for sexual variety does vary across cultures, and appears to be strongly linked to such evolutionary pressures as local sex ratio and fertility levels (see Schmitt, 2003c; Schmitt et al., in press).

It seems likely that the forces of gender socialization play at least some role in the development of many sex differences in human mating tendencies, and an evolutionary perspective on sex roles and gender socialization may help in fully explaining universal sex differences in the desire for sexual variety (see Schmitt, 2003c). As argued by many other theorists, only by integrating what is known from comparative psychology, human ethology, behavioral ecology, and reproductive biology with standard socialization explanations of human mating will a comprehensive theory of sex differences be possible (e.g., Geary, 1998; Mealey, 2000). At present, because the current ISDP findings reside amidst a vast array of historical studies supporting SST's view of sexual differentiation, as well as Trivers's (1972) theory of parental investment (including decades of research on nonhuman animals), and because numerous modern studies show evidence of special design in men's and women's psychology and physiology of short-term mating (see Baker \& Bellis, 1995; Gangestad \& Simpson, 2000; Schmitt, 2003b; Shackelford \& LeBlanc, 2001), the current evolutionary explanation of sex differences in the desire for sexual variety is regarded by the current authors as the most compelling explanation among alternate psychological theories.

\section{Conclusion}

This study provides the largest and most comprehensive test yet conducted on whether the sexes differ in the desire for sexual variety. The results are strong and conclusive-the sexes differ, and these differences appear to be universal. Men not only possess a greater desire than women do for a variety of sexual partners, men also require less time to elapse than women do before consenting to sexual intercourse, and men tend to more actively seek short-term mateships than women do. These sex differences are cross-culturally robust and statistically significant regardless of whether mean, median, distributional, or categorical indexes of sexual differentiation are evaluated. These sex differences are robust and significant regardless of the measures used to evaluate them. In conjunction with voluminous research findings from other investigators and other data sources (see Schmitt, Shackelford, \& Buss, 2001), the extant evidence supports two general conclusions: (a) men and women have evolved a menu of both short-term and long-term mating strategies, not a singular strategy as proposed by competing theories; and (b) the psychological design features of these strategies differ in men and women precisely in the ways initially predicted by SST (Buss \& Schmitt, 1993).

\section{References}

Alcock, J. (1993). Animal behavior (5th ed.). Sunderland, MA: Sinauer Associates.
Alcock, J., \& Gwynne, S. T. (1991). Evolution of insect mating systems: The impact of individual selectionist thinking. In W. J. Bailey \& J. Ridsdill-Smith (Eds.), Reproductive behavior in insects: Insects and populations (pp. 10-14). New York: Chapman \& Hall.

Alexander, R. D., \& Noonan, N. M. (1979). Concealment of ovulation, parental care, and human social interaction. In N. A. Chagnon \& W. Irons (Eds.), Evolutionary biology and human social behavior: An anthropological perspective (pp. 402-435). North Scituate, MA: Duxbury.

Andersson, M. (1994). Sexual selection. Princeton, NJ: Princeton University Press.

Archer, J., \& Lloyd, B. (2002). Sex and gender (2nd ed.). Cambridge, England: Cambridge University Press.

Bailey, J. M., Gaulin, S., Agyei, Y., \& Gladue, B. A. (1994). Effects of gender and sexual orientation on evolutionary relevant aspects of human mating psychology. Journal of Personality and Social Psychology, 66, 1081-1093.

Bailey, J. M., Kirk, K. M., Zhu, G., Dunne, M. P., \& Martin, N. G. (2000). Do individual differences in sociosexuality represent genetic or environmentally contingent strategies? Evidence from the Australian twin registry. Journal of Personality and Social Psychology, 78, 537-545.

Baker, R. R., \& Bellis, M. A. (1995). Human sperm competition. London: Chapman \& Hall.

Banfield, S., \& McCabe, M. P. (2001). Extra relationship involvement among women: Are they different from men? Archives of Sexual Behavior, 30, 119-142.

Barash, D. P., \& Lipton, J. E. (2001). The myth of monogamy. New York: Freeman.

Bateman, A. J. (1948). Intra-sexual selection in Drosophila. Heredity, 2, 349-368.

Bateson, P. (Ed.). (1983). Mate choice. Cambridge, England: Cambridge University Press.

Belsky, J. (1999). Modern evolutionary theory and patterns of attachment. In J. Cassidy \& P. R. Shaver (Eds.), Handbook of attachment (pp. 141-161). New York: Guilford Press.

Bess, B. E., \& Janus, S. S. (1976). Prostitution. In B. J. Sadock, H. I. Kaplan, \& A. M. Freedman (Eds.), The sexual experience (pp. 594 610). Baltimore: Williams \& Wilkins.

Bjorklund, D. F., \& Shackelford, T. K. (1999). Differences in parental investment contribute to important individual differences between men and women. Current Directions in Psychological Science, 8, 86-89.

Blumstein, P., \& Schwartz, P. (1983). American couples. New York: Morrow.

Brislin, R. W. (1980). Translation and content analysis of oral and written material. In H. C. Triandis \& J. W. Berry (Eds.), Handbook of crosscultural psychology (Vol. 1, pp. 389-444). Boston: Allyn \& Bacon.

Burley, N., \& Symanski, R. (1981). Women without: An evolutionary and cross-cultural perspective on prostitution. In R. Symanski (Ed.), The immoral landscape: Female prostitution in western societies (pp. 239274). Toronto, Canada: Butterworth-Heineman.

Buss, D. M. (1994). The evolution of desire. New York: Basic Books.

Buss, D. M. (1997). Sexual strategies theory: Historical origins and current status. Journal of Sex Research, 34, 19-31.

Buss, D. M., \& Schmitt, D. P. (1993). Sexual strategies theory: An evolutionary perspective on human mating. Psychological Review, 100, 204-232.

Carroll, J. L., Volk, K. D., \& Hyde, J. S. (1985). Differences between males and females in motives for engaging in sexual intercourse. Archives of Sexual Behavior, 14, 131-139.

Chisholm, J. S. (1996). The evolutionary ecology of attachment organization. Human Nature, 7, 1-38.

Church, A. T. (2001). Personality measurement in cross-cultural perspective. Journal of Personality, 69, 979-1006.

Clark, R. D. (1990). The impact of AIDS on gender differences in will- 
ingness to engage in casual sex. Journal of Applied Social Psychology, 20, 771-782.

Clark, R. D., \& Hatfield, E. (1989). Gender differences in receptivity to sexual offers. Journal of Psychology and Human Sexuality, 2, 39-55.

Clutton-Brock, T. H. (1991). The evolution of parental care. Princeton, NJ: Princeton University Press.

Clutton-Brock, T. H., \& Parker, G. A. (1992). Potential reproductive rates and the operation of sexual selection. The Quarterly Review of Biology, 67, 437-456.

Cohen, J. (1988). Statistical power analysis for the behavioral sciences (2nd ed.). Hillsdale, NJ: Erlbaum.

Cronk, L. (1999). That complex whole: Culture and the evolution of human behavior. Boulder, CO: Westview Press.

Daly, M., \& Wilson, M. (1988). Homicide. New York: Aldine de Gruyter.

Eagly, A. H. (1987). Sex differences in social behavior: A social-role interpretation. Hillsdale, NJ: Erlbaum.

Eagly, A. H., \& Wood, W. (1999). The origins of sex differences in human behavior: Evolved dispositions versus social roles. American Psychologist, 54, 408-423.

Ellis, B. J. (1992). The evolution of sexual attraction: Evaluative mechanisms in women. In J. H. Barkow, L. Cosmides, \& J. Tooby (Eds.), The adapted mind (pp. 267-288). New York: Oxford University Press.

Eysenck, H. J. (1976). Sex and personality. London: Open Books.

Gangestad, S. W. (2001). Adaptive design, selective history, and women's sexual motivations. In J. A. French, A. C. Kamil, \& D. W. Leger (Eds.), Evolutionary psychology and motivation (pp. 37-74). Lincoln: University of Nebraska Press.

Gangestad, S. W., \& Simpson, J. A. (1990). Toward an evolutionary history of female sociosexual variation. Special Issue: Biological foundations of personality: Evolution, behavioral genetics, and psychophysiology. Journal of Personality, 58, 69-96.

Gangestad, S. W., \& Simpson, J. A. (2000). The evolution of human mating: Trade-offs and strategic pluralism. Behavioral and Brain Sciences, 23, 573-587.

Gangestad, S. W., \& Thornhill, R. (1997). Human sexual selection and developmental stability. In J. A. Simpson \& D. T. Kenrick (Eds.), Evolutionary social psychology (pp. 169-195). Mahwah, NJ: Erlbaum.

Geary, D. C. (1998). Male, female: The evolution of human sex differences. Washington, DC: American Psychological Association.

Greiling, H., \& Buss, D. M. (2000). Women's sexual strategies: The hidden dimension of short-term mating. Personality and Individual Differences, 28, 929-963.

Guttentag, M., \& Secord, P. F. (1983). Too many women? The sex ratio question. Beverly Hills, CA: Sage.

Gwynne, D. T. (1984). Sexual selection and sexual differences in Mormon crickets. Evolution, 38, 1011-1022.

Harvey, P. H., \& Reynolds, J. D. (1994). Sexual selection and the evolution of sex differences. In R. V. Short \& E. Balaban (Eds.), The difference between the sexes (pp. 51-66). Cambridge, England: Cambridge University Press.

Hassebrauck, M. (1998). The visual process method: A new method to study physical attractiveness. Evolution and Human Behavior, 19, 111123.

Hazan, C., \& Diamond, L. M. (2000). The place of attachment in human mating. Review of General Psychology, 4, 186-204.

Hazan, C., \& Zeifman, D. (1999). Pair bonds as attachments: Evaluating the evidence. In J. Cassidy \& P. R. Shaver (Eds.), Handbook of attachment (pp. 336-354). New York: Guilford Press.

Heine, S. J., Lehman, D. R., Peng, K., \& Greenholtz, J. (2002). What's wrong with cross-cultural comparisons of subjective Likert scales? The reference-group effect. Journal of Personality and Social Psychology, 82, 903-918.

Hinde, R. A. (1984). Why do the sexes behave differently in close relationships? Journal of Social and Personal Relationships, 1, 471-501.

Hoyle, R. H., Fejfar, M. C., \& Miller, J. D. (2000). Personality and sexual risk taking: A quantitative review. Journal of Personality, 68, 12031231.

Hrdy, S. B. (1981). The woman that never evolved. Cambridge, MA: Harvard University Press.

Hyde, J. S. (1986). Gender differences in aggression. In J. S. Hyde \& M. C. Linn (Eds.), The psychology of gender: Advances through meta-analysis (pp. 51-66). Baltimore: Johns Hopkins University Press.

Kelly, R. L. (1995). The foraging spectrum: Diversity in hunter-gatherer lifeways. Washington, DC: Smithsonian Institution Press.

Kenrick, D. T., Neuberg, S. L., Zierk, K. L., \& Krones, J. M. (1994). Evolution and social cognition: Contrast effects as a function of sex, dominance, and physical attractiveness. Personality and Social Psychology Bulletin, 20, 210-217.

Kenrick, D. T., Sadalla, E. K., Groth, G., \& Trost, M. R. (1990). Evolution, traits, and the stages of human courtship: Qualifying the parental investment model. Special issue: Biological foundations of personality: Evolution, behavioral genetics, and psychophysiology. Journal of Personality, 58, 97-116.

Kenrick, D., Sadalla, E., \& Keefe, R. (1998). Evolutionary cognitive psychology: The missing heart of modern cognitive science. In C. Crawford \& D. Krebs (Eds.), Handbook of evolutionary psychology (pp. 485-514). Mahwah, NJ: Erlbaum.

Klusmann, D. (2002). Sexual motivation and the duration of partnership. Archives of Sexual Behavior, 31, 275-287.

Knodel, J., Low, B., Saengtienchai, C., \& Lucas, R. (1997). An evolutionary perspective on Thai sexual attitudes and behavior. Journal of Sex Research, 34, 292-303.

Lancaster, J. B. (1989). Evolutionary and cross-cultural perspectives on single-parenthood. In R. W. Bell \& N. J. Bell (Eds.), Interfaces in psychology (pp. 63-72). Lubbock: Texas Tech University Press.

Landolt, M. A., Lalumiere, M. L., \& Quinsey, V. L. (1995). Sex differences in intra-sex variations in human mating tactics: An evolutionary approach. Ethology and Sociobiology, 16, 3-23.

Laumann, E. O., Gagnon, J. H., Michael, R. T., \& Michaels, S. (1994). The social organization of sexuality. Chicago: University of Chicago Press.

Le Boeuf, B. J. (1974). Male-male competition and reproductive success in elephant seals. American Zoologist, 14, 163-176.

Leitenberg, H., \& Henning, K. (1995). Sexual fantasy. Psychological Bulletin, 117, 469-496.

Lovejoy, O. (1981, January). The origin of Man. Science, 211, 341-350.

Low, B. S. (1989). Cross-cultural patterns in the training of children: An evolutionary perspective. Journal of Comparative Psychology, 103, 311-319.

Malamuth, N. M. (1996). Sexually explicit media, gender differences, and evolutionary theory. Journal of Communication, 46, 8-31.

Maynard Smith, J. (1977). Parental investment: A prospective analysis. Animal Behavior, 25, 1-9.

Mealey, L. (2000). Sex differences: Developmental and evolutionary strategies. San Diego, CA: Academic Press.

Miller, L. C., \& Fishkin, S. A. (1997). On the dynamics of human bonding and reproductive success: Seeking windows on the adapted-for humanenvironment interface. In J. A. Simpson \& D. T. Kenrick (Eds.), Evolutionary social psychology (pp. 197-235). Mahwah, NJ: Erlbaum.

Miller, L. C., Putcha-Bhagavatula, A., \& Pedersen, W. C. (2002). Men's and women's mating preferences: Distinct evolutionary mechanisms? Current Directions in Psychological Science, 11, 88-93.

Mills, S., Saidel, T., Bennett, A., Rehle, T., Hogle, J., Brown, T., \& Magnani, R. (1998). HIV risk behavioral surveillance: A methodology for monitoring behavioral trends. AIDS, 12, S37-S46.

Mize, S. J. S., Robinson, B. E., Bockting, W. O., \& Scheltema, K. E. (2002). Meta-analysis of the effectiveness of HIV prevention interventions for women. AIDS CARE, 14, 163-180.

Munroe, R. L., \& Munroe, R. H. (1997). A comparative anthropological perspective. In J. W. Berry, Y. H. Poortinga, \& J. Pandey (Eds.), 
Handbook of cross-cultural psychology (2nd ed., Vol. 1, pp. 171-213). Boston: Allyn \& Bacon.

Oliver, M. B., \& Hyde, J. S. (1993). Gender differences in sexuality: A meta-analysis. Psychological Bulletin, 114, 29-51.

Pedersen, F. A. (1991). Secular trends in human sex ratios: Their influence on individual and family behavior. Human Nature, 2, 271-291.

Pedersen, W. C., Miller, L. C., Putcha-Bhagavatula, A. D., \& Yang, Y. (2002). Evolved sex differences in the number of partners desired? The long and the short of it. Psychological Science, 13, 157-161.

Quinn, N. (1977). Anthropological studies on women's status. Annual Review of Anthropology, 6, 181-225.

Regan, P. C. (1998a). Minimum mate selection standards as a function of perceived mate value, relationship context, and gender. Journal of Psychology and Human Sexuality, 10, 53-73.

Regan, P. C. (1998b). What if you can't get what you want? Willingness to compromise ideal mate selection standards as a function of sex, mate value, and relationship context. Personality and Social Psychology Bulletin, 24, 1294-1303.

Regan, P. C., \& Berscheid, E. (1997). Gender differences in characteristics desired in a potential sexual and marriage partner. Journal of Psychology and Human Sexuality, 9, 25-37.

Reynolds, J. D. (1987). Mating system and nesting biology of the rednecked phalarope Phalaropus lobatus: What constrains polyandry? Isis, 129, 225-242.

Salmon, C., \& Symons, D. (2001). Warrior lovers: Erotic fiction, evolution, and female sexuality. London: Weidenfeld \& Nicolson.

Scheib, J. E. (1997, June). Context-specific mate choice criteria: Women's trade-offs in the contexts of long-term and extra-pair mateships. Paper presented at the Annual Meeting of the Human Behavior and Evolution Society, University of Arizona, Tucson, AZ.

Schmitt, D. P. (2002a). A meta-analysis of sex differences in romantic attraction: Do rating contexts affect tactic effectiveness judgments? British Journal of Social Psychology, 41, 387-402.

Schmitt, D. P. (2002b). Are sexual promiscuity and relationship infidelity linked to different personality traits across cultures? Findings from the International Sexuality Description Project. In W. Lonner, D. L. Dinnel, S. A. Hayes, \& D. N. Sattler (Eds.), Online readings in psychology and culture. Western Washington University, Department of Psychology, Center for Cross-Cultural Research Web site: http://www.wwu.edu/ $\sim$ culture

Schmitt, D. P. (2003a). Is short-term mating caused by insecure romantic attachment? A test of competing evolutionary theories. Manuscript submitted for publication.

Schmitt, D. P. (2003b). Short-term mating desires are related to finger length ratios, waist-to-hip ratios, and body symmetry in college-aged men and women. Manuscript submitted for publication.

Schmitt, D. P. (2003c). Sociosexuality from Argentina to Zimbabwe: A 48-nation study of sex, culture, and the dynamics of human mating. Manuscript submitted for publication.

Schmitt, D. P., Alcalay, L., Allensworth, M., Allik, J., Ault, L., Austers, I., et al. (in press). Are men universally more dismissing than women? Gender differences in romantic attachment across 62 cultural regions. Personal Relationships.

Schmitt, D. P., \& Buss, D. M. (1996). Strategic self-promotion and competitor derogation: Sex and context effects on the perceived effectiveness of mate attraction tactics. Journal of Personality and Social Psychology, 70, 1185-1204.

Schmitt, D. P., \& Buss, D. M. (2001). Human mate poaching: Tactics and temptations for infiltrating existing mateships. Journal of Personality and Social Psychology, 80, 894-917.

Schmitt, D. P., Couden, A., \& Baker, M. (2001). The effects of sex and temporal context on feelings of romantic desire: An experimental evaluation of Sexual Strategies Theory. Personality and Social Psychology Bulletin, 27, 833-847.

Schmitt, D. P., Shackelford, T. K., \& Buss, D. M. (2001). Are men really more "oriented" toward short-term mating than women? A critical review of research and theory. Psychology, Evolution and Gender, 3, 211-239.

Schmitt, D. P., Shackelford, T. K., Duntley, J., Tooke, W., \& Buss, D. M. (2001). The desire for sexual variety as a key to understanding basic human mating strategies. Personal Relationships, 8, 425-455.

Schmitt, D. P., Shackelford, T. K., Duntley, J., Tooke, W., Buss, D. M., Fisher, M. L., et al. (2002). Is there an early 30s peak in female sexual desire: Cross-sectional evidence from the United States and Canada. The Canadian Journal of Human Sexuality, 11, 1-18.

Shackelford, T. K., \& Buss, D. M. (1997). Marital satisfaction in evolutionary psychology perspective. In R. J. Sternberg \& M. Hojjat (Eds.), Satisfaction in close relationships (pp. 7-25). New York: Guilford Press.

Shackelford, T. K., \& LeBlanc, G. J. (2001). Sperm competition in insects, birds, and humans: Insights from a comparative evolutionary perspective. Evolution and Cognition, 7, 194-202.

Simpson, J. A., \& Gangestad, S. W. (1991). Individual differences in sociosexuality: Evidence for convergent and discriminant validity. Journal of Personality and Social Psychology, 60, 870-883.

Simpson, J. A., \& Gangestad, S. W. (1992). Sociosexuality and romantic partner choice. Journal of Personality, 60, 31-51.

Simpson, J. A., Gangestad, S. W., Christensen, P. N., \& Leck, K. (1999). Fluctuating asymmetry, sociosexuality, and intrasexual competitive tactics. Journal of Personality and Social Psychology, 76, 159-172.

Smith, R. L. (1984). Human sperm competition. In R. L. Smith (Ed.), Sperm competition and the evolution of animal mating systems (pp. 601-659). New York: Academic Press.

Speed, A., \& Gangestad, S. W. (1997). Romantic popularity and mate preferences: A peer-nomination study. Personality and Social Psychology Bulletin, 23, 928-935.

Sprecher, S., Sullivan, Q., \& Hatfield, E. (1994). Mate selection preferences: Gender differences examined in a national sample. Journal of Personality and Social Psychology, 66, 1074-1080.

Symons, D. (1979). The evolution of human sexuality. New York: Oxford University Press.

Townsend, J. M. (1995). Sex without emotional involvement: An evolutionary interpretation of sex differences. Archives of Sexual Behavior, 24, 173-205.

Trivers, R. (1972). Parental investment and sexual selection. In B. Campbell (Ed.), Sexual selection and the descent of man: 1871-1971 (pp. 136-179). Chicago: Aldine-Atherton.

Trivers, R. (1985). Social evolution. Menlo Park, CA: Benjamin Cummings.

Walter, A. (1997). The evolutionary psychology of mate selection in Morocco: A multivariate analysis. Human Nature, 8, 113-137.

Weinhardt, L. S., Carey, M. P., Johnson, B. T., \& Bickham, N. L. (1999). Effects of HIV counseling and testing on sexual risk behavior: A meta-analytic review of published research, 1985-1997. American Journal of Public Health, 89, 1397-1405.

Wiederman, M. W. (1997). Extramarital sex: Prevalence and correlates in a national survey. The Journal of Sex Research, 34, 167-174.

Wiederman, M. W., \& Dubois, S. L. (1998). Evolution and sex differences in preferences for short-term mates: Results from a policy capturing study. Evolution and Human Behavior, 19, 153-170.

Wilcox, R. R. (1987). New statistical procedures for the social sciences. Hillsdale, NJ: Erlbaum.

Wilcox, R. R. (1996). Statistics for the social sciences. San Diego, CA: Academic Press.

Wilson, G. D. (1987). Male-female differences in sexual activity, enjoyment, and fantasies. Personality and Individual Differences, 8, 125-127.

Wright, T. M., \& Reise, S. P. (1997). Personality and unrestricted sexual behavior: Correlations of sociosexuality in Caucasian and Asian college students. Journal of Research in Personality, 31, 166-192.

Zeifman, D., \& Hazan, C. (1997). Attachment: The bond in pair-bonds. In J. Simpson \& D. T. Kenrick (Eds.), Evolutionary social psychology (pp. 237-263). Hillsdale, NJ: Erlbaum. 
The 118 coauthors of this article include: Lidia Alcalay, Pontificia Universidad Católica de Chile, Santiago, Chile; Jüri Allik, University of Tartu, Tartu, Estonia; Lara Ault, University of Louisville, USA; Ivars Austers, University of Latvia, Riga, Latvia; Kevin L. Bennett, University of New Mexico, USA; Gabriel Bianchi, Slovak Academy of Sciences, Bratislava, Slovak Republic; Fredric Boholst, University of San Carlos, Cebu City, Philippines; Mary Ann Borg Cunen, University of Malta, Msida, Malta; Johan Braeckman, Ghent University, Ghent, Belgium; Edwin G. Brainerd Jr., Clemson University, USA; Leo Gerard A. Caral, University of San Carlos, Cebu City, Philippines; Gabrielle Caron, Université Laval, Québec, Québec, Canada; Maria Martina Casullo, University of Buenos Aires, Buenos Aires, Argentina; Michael Cunningham, University of Louisville, USA; Ikuo Daibo, Osaka University, Osaka, Japan; Charlotte De Backer, Ghent University, Ghent, Belgium; Eros De Souza, Illinois State University, USA; Rolando Diaz-Loving, National Autonomous University of Mexico, Mexico City, Mexico; Gláucia Diniz, University of Brasilia, Brasilia, Brazil; Kevin Durkin, The University of Western Australia, Crawley, Australia; Marcela Echegaray, University of Lima, Lima, Peru; Ekin Eremsoy, Bogaziçi Üniversitesi, Istanbul, Turkey; Harald A. Euler, University of Kassel, Kassel, Germany; Ruth Falzon, University of Malta, Msida, Malta; Maryanne L. Fisher, York University, Toronto, Ontario, Canada; Dolores Foley, University of Queensland, Brisbane, Australia; Douglas P. Fry, Åbo Akademi University, Turku, Finland; Sirpa Fry, Åbo Akademi University, Turku, Finland; M. Arif Ghayur, AlAkhawayn University, Ifrane, Morocco; Debra L. Golden, University of Hawaii-Manoa, USA; Karl Grammer, Ludwig-Boltzmann-Institute for Urban Ethology, Vienna, Austria; Liria Grimaldi, University of Catania, Catania, Italy; Jamin Halberstadt, University of Otago, Dunedin, New Zealand; Dora Herrera, University of Lima, Lima, Peru; Janine Hertel, Technische Universität Chemnitz, Chemnitz, Germany; Heather Hoffmann, Knox College, USA; Danica Hooper, University of Queensland, Brisbane, Australia; Zuzana Hradilekova, Comenius University, Bratislava, Slovak Republic; Jasna Hudek-Kene-evi, University of Rijeka, Rijeka, Croatia; Jas Jaafar, University of Malaya, Kuala Lumpur, Malaysia; Margarita Jankauskaite, Vilnius University, Vilnius, Lithuania; Heidi Kabangu-Stahel, Centre d'Enseignement les Gazelles, Kinsasha-Gombe, Democratic Republic of the Congo; Igor Kardum, University of Rijeka, Rijeka, Croatia; Brigitte Khoury, American University of Beirut, Beirut, Lebanon; Hayrran Kwon, Kwangju Health College, Shinchang-dong, Republic of Korea; Kaia Laidra, University of Tartu, Tartu, Estonia; AntonRupert Laireiter, Institute of Psychology, University of Salzburg, Salzburg, Austria; Dustin Lakerveld, University of Utrecht, Utrecht, the Netherlands; Ada Lampert, The Ruppin Institute, Emek Hefer, Israel; Maryanne Lauri, University of Malta, Msida, Malta; Marguerite Lavallée, Université Laval, Québec, Québec, Canada; Suk-Jae Lee, National Computerization Agency, Yongingsi Gyonggido, Republic of Korea; Luk Chung Leung, City University of Hong Kong, Hong Kong; Kenneth D. Locke, University of Idaho, USA; Vance Locke, The University of Western Australia, Crawley, Australia; Ivan Luksik, Slovak Academy of Sciences, Bratislava, Slovak Republic; Ishmael Magaisa, University of Zimbabwe, Harare, Zimbabwe; Dalia Marcinkeviciene, Vilnius University, Vilnius, Lithuania; André Mata, University of Lisbon, Lisbon, Portugal; Rui Mata, University of Lisbon, Lisbon, Portugal; Barry McCarthy, University of Central Lancashire, Preston, United Kingdom; Michael E. Mills, Loyola Marymount University, USA; João Moreira, University of Lisbon, Lisbon, Portugal; Sérgio
Moreira, University of Lisbon, Lisbon, Portugal; Miguel Moya, University of Granada, Granada, Spain; M. Munyae, University of Botswana, Gaborone, Botswana; Patricia Noller, University of Queensland, Brisbane, Australia; Adrian Opre, Babes Bolyai University, Cluj Napoca, Romania; Alexia Panayiotou, University of Cyprus, Nicosia, Cyprus; Nebojsa Petrovic, University of Belgrade, Belgrade, Serbia; Karolien Poels, Ghent University, Ghent, Belgium; Miroslav Popper, Slovak Academy of Sciences, Bratislava, Slovak Republic; Maria Poulimenou, KPMG Kyriacou Counsultants SA, Athens, Greece; Volodymyr P'yatokha, Volyn Regional Hospital, Lutsk, Volyn, Ukraine; Michel Raymond, Université de Montpellier II, Montpellier, France; Ulf-Dietrich Reips, Universität Zürich, Zürich, Switzerland; Susan E. Reneau, University of Alabama, USA; Sofia Rivera-Aragon, National Autonomous University of Mexico, Mexico City, Mexico; Wade C. Rowatt, Baylor University, USA; Willibald Ruch, Queens University Belfast, Belfast, Northern Ireland; Velko S. Rus, University of Ljubljana, Ljubljana, Slovenia; Marilyn P. Safir, University of Haifa, Haifa, Israel; Sonia Salas, Universidad de La Serena, La Serena, Chile; Fabio Sambataro, University of Catania, Catania, Italy; Kenneth N. Sandnabba, Åbo Akademi University, Turku, Finland; Marion K. Schulmeyer, Universidad Privada de Santa Cruz de la Sierra, Santa Cruz, Bolivia; Astrid Schütz, Technische Universität Chemnitz, Chemnitz, Germany; Tullio Scrimali, University of Catania, Catania, Italy; Todd K. Shackelford, Florida Atlantic University, USA; Phillip R. Shaver, University of California at Davis, USA; Francis Sichona, University of Dar es Salaam, Dar es Salaam, Tanzania; Franco Simonetti, Pontificia Universidad Católica de Chile, Santiago, Chile; Tilahun Sineshaw, Ramapo College of New Jersey, USA; Tom Speelman, Ghent University, Ghent, Belgium; Spyros Spyrou, Cyprus College, Nicosia, Cyprus; H. Canan Sümer, Middle East Technical University, Ankara, Turkey; Nebi Sümer, Middle East Technical University, Ankara, Turkey; Marianna Supekova, Slovak Academy of Sciences, Bratislava, Slovak Republic; Tomasz Szlendak, Nicholas Copernicus University, Torun, Poland; Robin Taylor, University of the South Pacific, Suva, Fiji; Bert Timmermans, Vrije Universiteit Brussel, Brussels, Belgium; William Tooke, SUNYPlattsburgh, USA; Ioannis Tsaousis, University of the Aegean, Mytilene, Lesvos, Greece; F. S. K. Tungaraza, University of Dar es Salaam, Dar es Salaam, Tanzania; Griet Vandermassen, Ghent University, Ghent, Belgium; Tim Vanhoomissen, Vrije Universiteit Brussel, Brussels, Belgium; Frank Van Overwalle, Vrije Universiteit Brussel, Brussels, Belgium; Ine Vanwesenbeeck, Netherlands Institute of Social Sexological Research, Utrecht, the Netherlands; Paul L. Vasey, University of Lethbridge, Lethbridge, Alberta, Canada; João Verissimo, University of Lisbon, Lisbon, Portugal; Martin Voracek, University of Vienna Medical School, Vienna, Austria; Wendy W. N. Wan, University of Hong Kong, Hong Kong; Ta-Wei Wang, Yuan Ze University, Chung-Li, Taiwan; Peter Weiss, Charles University, Prague, Czech Republic; Andik Wijaya, Couple Clinic Indonesia, Surabaya, Indonesia; Liesbeth Woertman, Utrecht University, Utrecht, the Netherlands; Gahyun Youn, Chonnam National University, Kwangju, Republic of Korea; Agata Zupanèiè, University of Ljubljana, Ljubljana, Slovenia.
Received July 17, 2002

Revision received February 17, 2003 Accepted February 21, 2003 